\title{
استجابة صفات محصول السمسم (Sesamum indicum L.) و مكوناته لبعض المعاملات الزراعية
}

\author{
ياسر محمد علي أحمد 1، رقيبة محمد عبد الله فاضل 2، زياد عثمان سالم أحمد2،
}

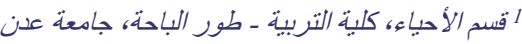

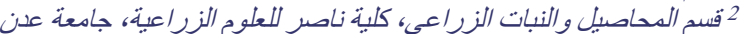

*iadothmanaljuri@gmail.com الباحث الممثل: زياد عثمان سالم أحمد؛ البريد الاككتروني: استلم في: 08 نوفمبر 2020 / قبل في: 21 ديسمبر 2020 / نشر في: 30 ديسمبر 2020

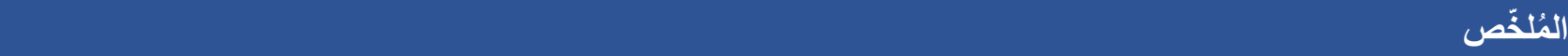

أجريت تجربة حقلية في مزر عة قرية الثعلب بمحافظة لحج في الموسمين الزر اعيين 2014 و و2015 مو لدر اسة استجابة السمسم المحلي صنف

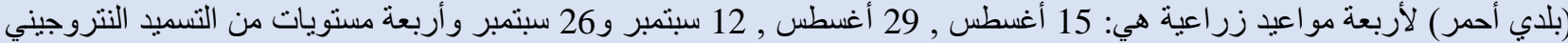

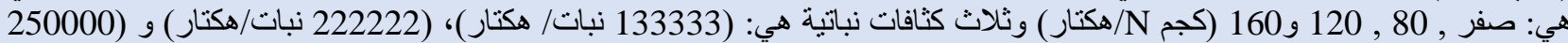

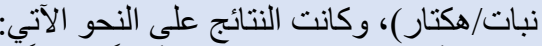

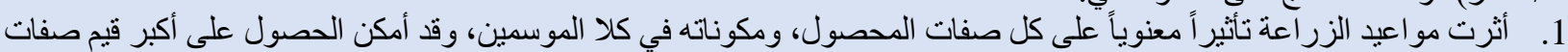

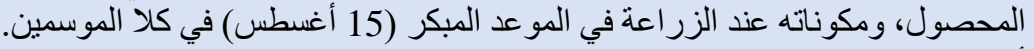

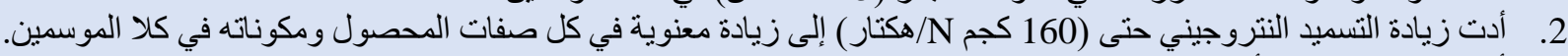

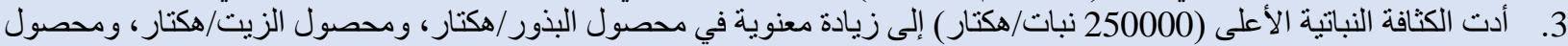
البروتين الخام/هكتار.

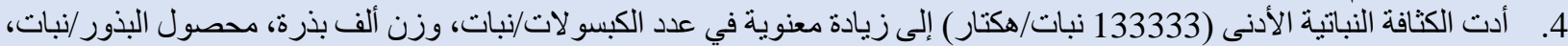

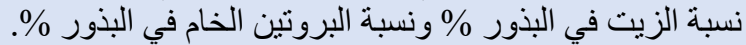
5. أدت الكثافة النباتية الوسطى (222222 نبات/هكتار) إلى زيادة معنوية في نسبة البروتين الخام في البذور \%)، ومحصول البروتين الخام (طن متري/هكتار) .

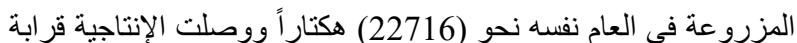

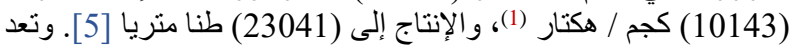

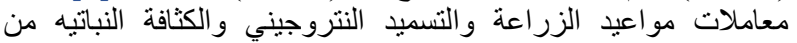

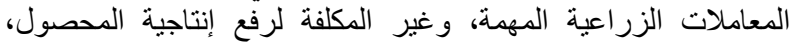

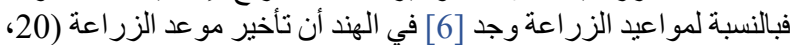

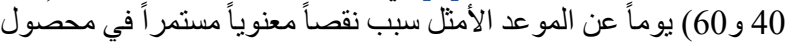

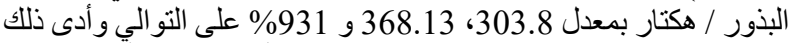

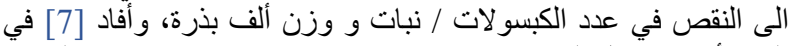

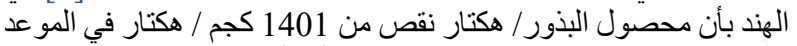

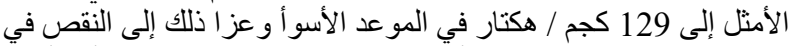

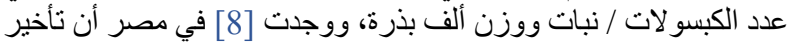

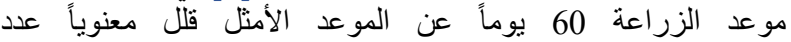

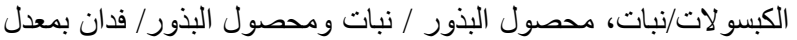

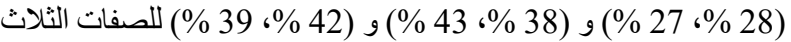

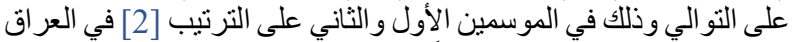

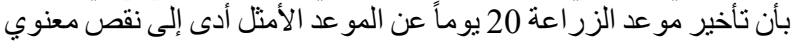

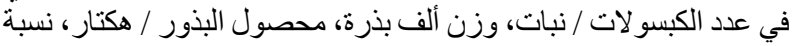

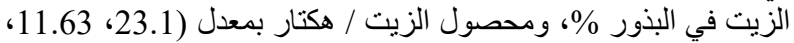

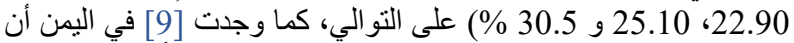

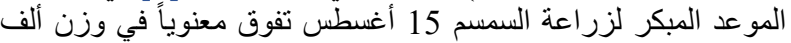

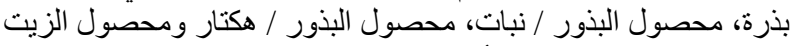

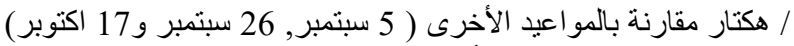

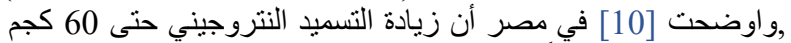

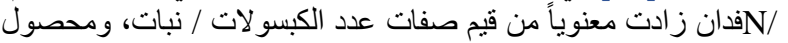

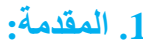

السمسم (Sesamum indicum L.) من محاصيل الزيت المهية، وينتمي

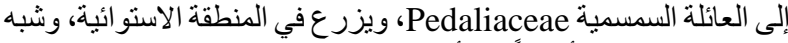

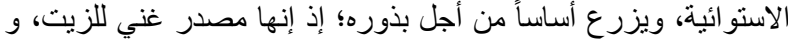

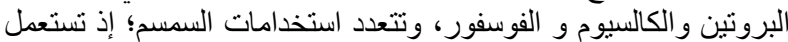

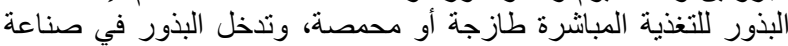

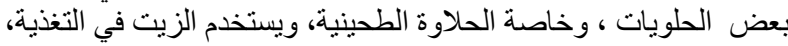

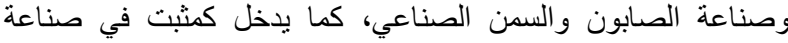

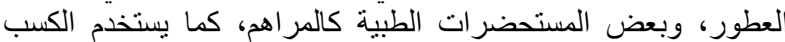

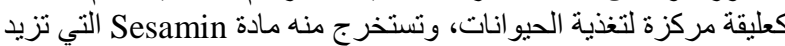

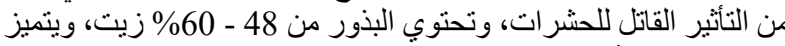

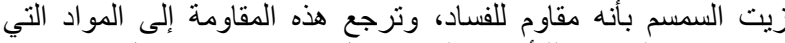

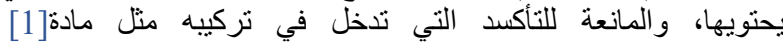
Sescimolin

.[2] $\% 25$

و أهم البلدان المنتجة له في العالم الهند، السودان، البيرو، والصين. وتعد بعديا

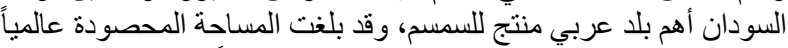

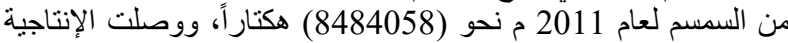

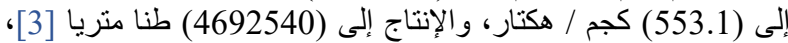

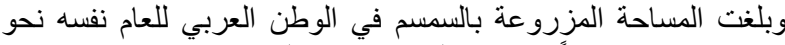

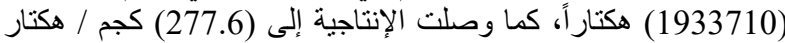

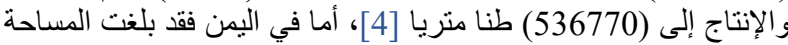




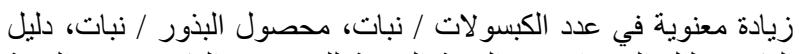

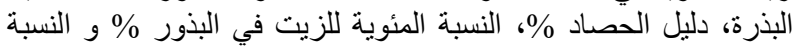

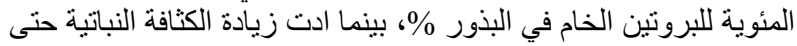

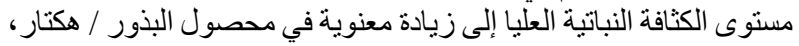
ومحصول الزيت / هكتار.

2.

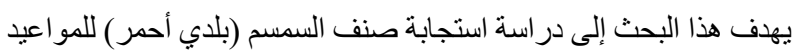

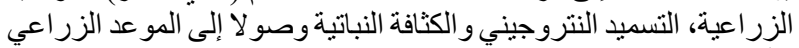

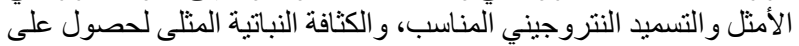

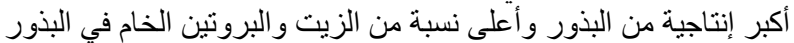
\%، و أعلى محصول للزيت و البروتين الخام (طن متري / هكتار ).

\section{3. مواد وطر ائق البيش:}

نُفِّنت تجربة حقلية في قرية الثعلب بمحافظة لحج في الموسمين الزر اعيين

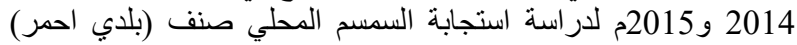

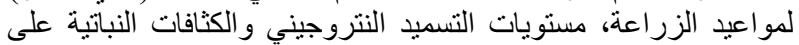
النمو، المحصول ومكوناته وقد نفذت التجربة في تصميم القطع المنشقة مرتين Split-Split plot design بنظام القطاعات كاملة العشو ائية

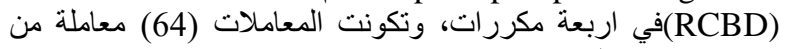

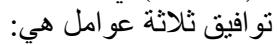

أـ الكثافة النباتية: اشتملت معاملات الكثافة النباتية على ثناثلاث كثافات

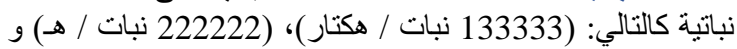

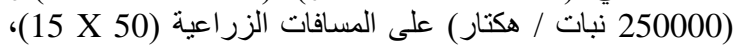

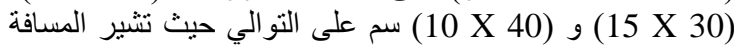

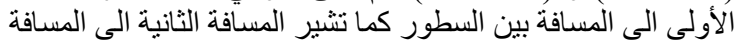

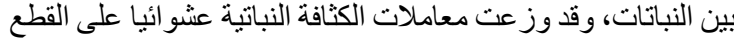
الرئيسية.

ب- مستويات التسميد النتروجيني: اشتملت مستويات التسميد

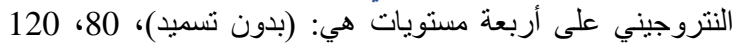

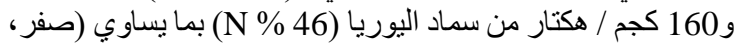

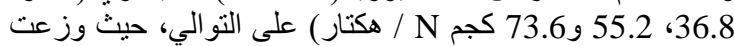
معاملات التسميد عشو ائيا على القطع الفرعية.

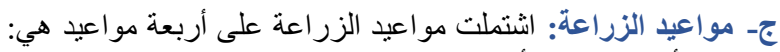

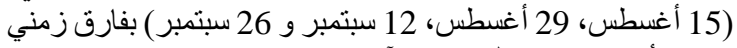

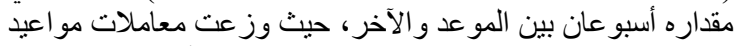

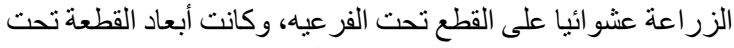

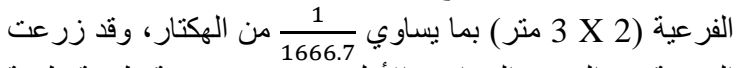

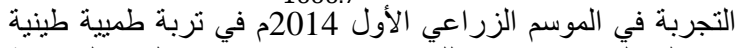

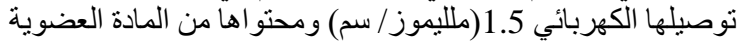

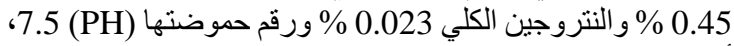

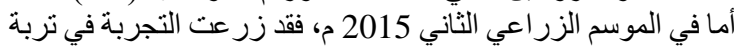

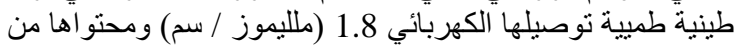
المادة العضوية 0.60 \% و والنتروجين الكلي 0.235 \% حموضنتها (1) 7.9 (1) جدولة

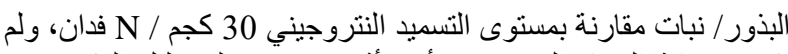

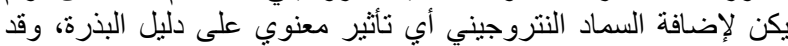

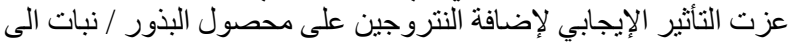

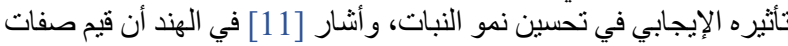

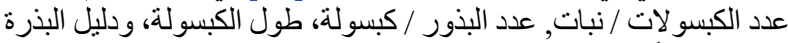

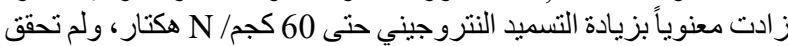

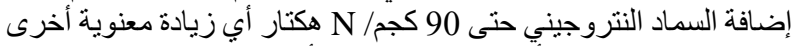

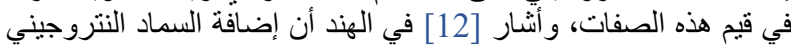

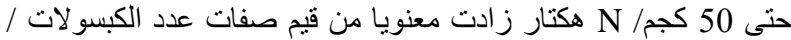

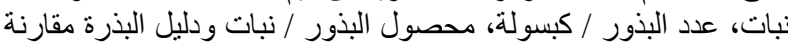

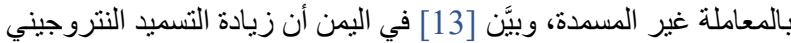

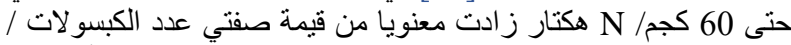

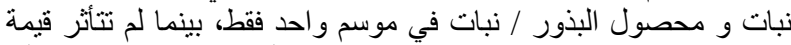

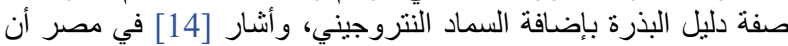

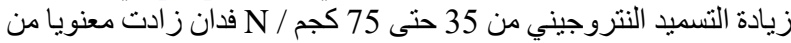

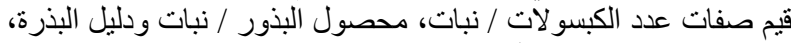

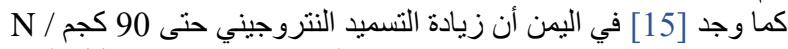

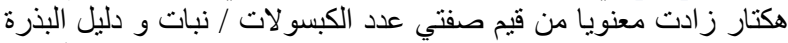

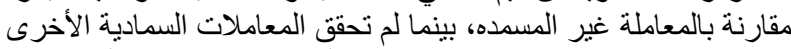

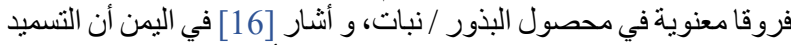

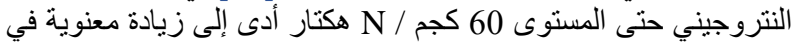

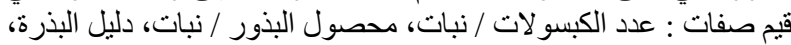

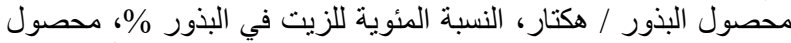

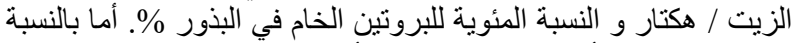

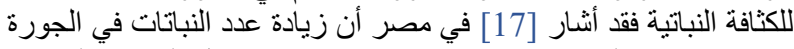

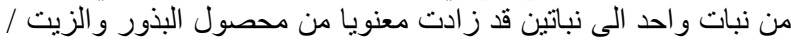

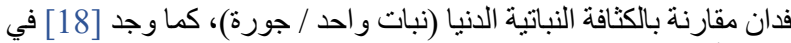

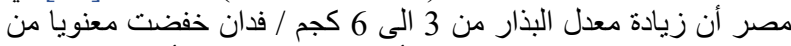

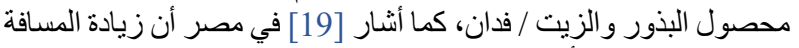

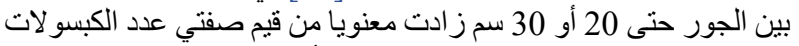

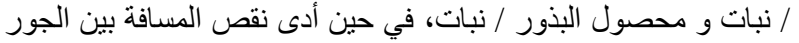

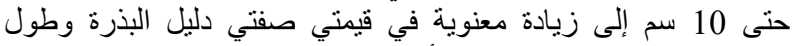

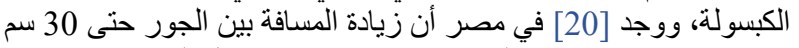

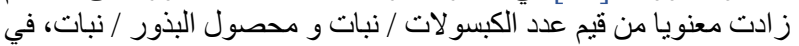

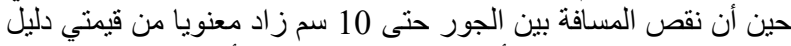

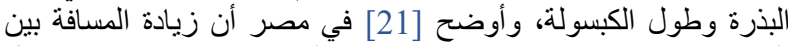

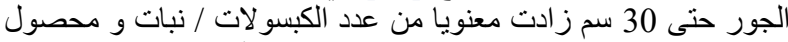

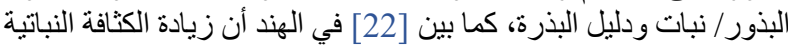

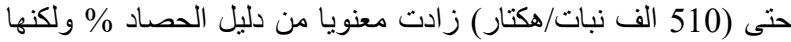

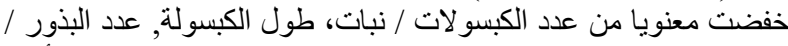

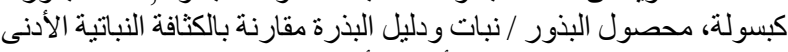

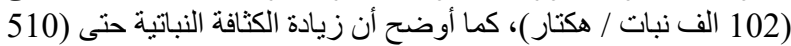

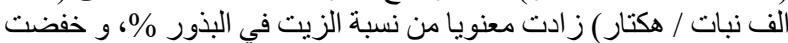

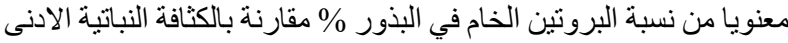
(102 الف نبات / هكتار ).

ووجد [15] في اليمن أن زيادة معدل البذار حتى (10 كجم بذور/ هكتار)

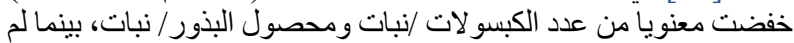

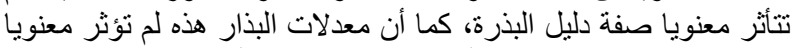

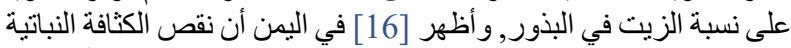

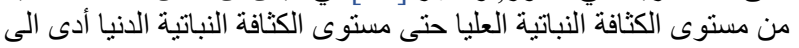

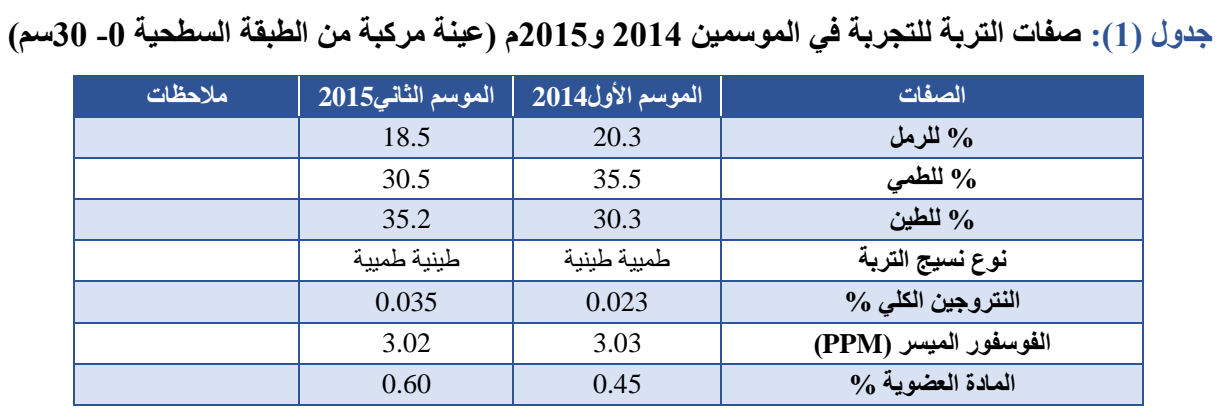




\begin{tabular}{|c|c|c|c|}
\hline مستخلص مائي 1:1* & 1.8 & 1.5 & التوصيل الكهربائي (ملليموز / سم) \\
\hline \multirow[t]{2}{*}{ مستخلص مائي 1:1 } & 7.9 & 7.5 & رقم حموضة التربة (PH) \\
\hline & & & الكايتونات الذائبة في الماء (مليمكافئ / لتر) \\
\hline مستخلص مائي 1:1 & 1.50 & 2.50 & الكالسيوم Ca-2 \\
\hline \multirow[t]{2}{*}{ 1:1 مستخلص مائي } & 1.50 & 1.20 & المغتسيوم Mg+2 \\
\hline & & & الاينونات الذائبة في الماء( مليمكافئ / لتر) \\
\hline مستخلص مائي 1:1 & 12.5 & 10.5 & أيون الكبريتات So \\
\hline 1:1 مستخلص مائي & 1.2 & 2.3 & أيون الكلوريد CL \\
\hline مستخلص مائي 1:1 & 2.3 & 1.7 & أيون البيكربونات \\
\hline مستخلص مائي 1:1 & 0.06 & 0.05 & أيون الكربونات CO \\
\hline
\end{tabular}

المصدر: المختبر المركزي ـ كلية ناصر للعلوم الزر اعية - جامعة عدن.

\section{جدول (3): نتائج اختبار نسبة الإنبات \% ب لصنف السمسم المستخدم في التجربة بلاي أحمر خلال الموسمين 2014 و2015م.}

\begin{tabular}{|c|c|}
\hline نسبة الأبات & الموسم الزراعي \\
\hline$\% 97$ & الأول 2014 \\
\hline$\% 95$ & الثاني 2015 \\
\hline
\end{tabular}

المصدر : مختبر قسم المحاصيل و النبات الزر اعي ـ كلية ناصر عدن للعلوم

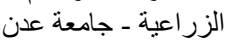

الصفات المدروسة: صفات المحصول ومكوناته

$$
\text { 1- عدد الكبسولات / نبات /كبسولة }
$$

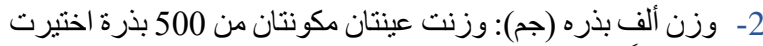

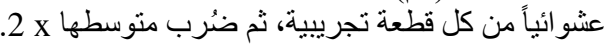

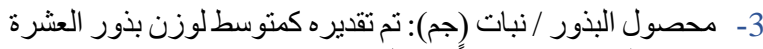

نباتات المختارة عشو ائياً من كل قطعة تجريبية.

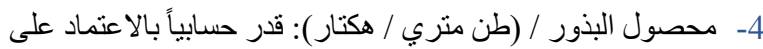

محصول بذور القطعة التجريبية كلها.

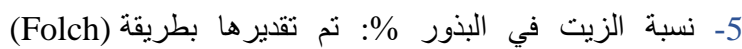

لاستخلاص الزيت على البارد بواسطة المذيبات العضوية [23].

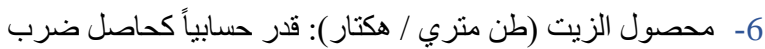

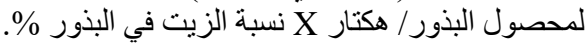

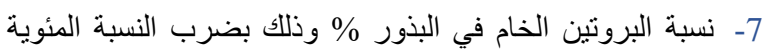

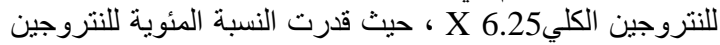

الكلي بالطريقة اللونية باستخدام جهاز Spectrophotometer

وذللك حسب [23].

8- محصول البروتين الخام (طن متري / هكتار) : قدر حسابياً كحاصل فئل

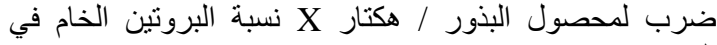

$$
\text { البذور0\%. }
$$

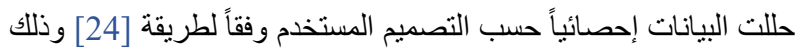

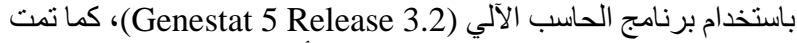
المقارنة بين متوسطات المعاملات باستخدام أقل فرق معنوي (L.S.D)

عند مستوى احتمال 55 \% [25]
وقد اجري تحليل كيميائي لمياه الري الجوفية المستخدمة في ري التجربة

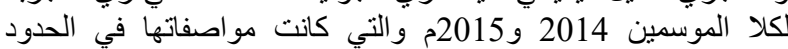

المسموح بها لري السمسم جدول (2) ولمين

جدول (2): التحليل الكيميائي لمياه بئر مزرعة كلية ناصر للعلوم

\begin{tabular}{|c|c|c|}
\hline الموسم الثيأي & الموسم الأول & التحيل الفيزيائي \\
\hline 8.1 & 8 & رقم الحموضة (PH) \\
\hline 0.70 & 0.65 & التوصيل الكهربائي (E.C)(ملليموز/ \\
\hline & & التحليل الكيميائي (مليمكافى / لتر) \\
\hline 1.07 & 2.03 & البوتاسيوم (K) \\
\hline 6.30 & 5.20 & الصوديوم (Na) \\
\hline 0.50 & 0.20 & الماغنسيوم (Mg) \\
\hline 0.40 & 0.30 & الكالسيوم (Ca) \\
\hline 1.50 & 1.20 & 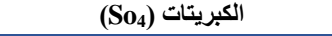 \\
\hline 0.50 & 0.20 & الكلوريد (CL) \\
\hline 0.40 & 0.30 & الكربونات (HCO \\
\hline
\end{tabular}
الزراعية للموسمين 2014 و2015م لمئين

تمت الزراعة في سطور بالطريقة الجافة وفقاً للمعاملات التجريبية،

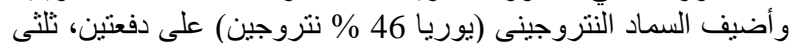

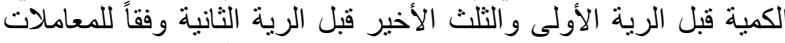

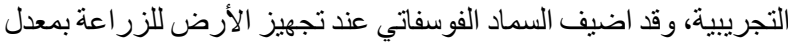

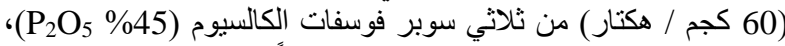

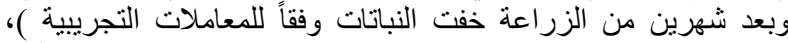

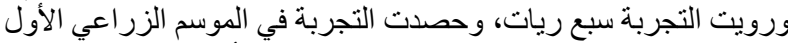
2014 م في 2014/11/15م للموعد الزراعي الزئي الأول، 2014/12/12

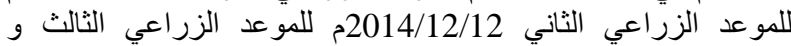

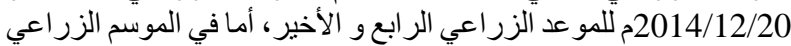

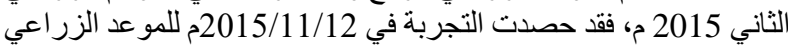

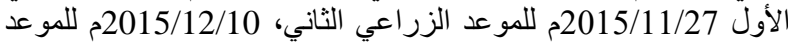

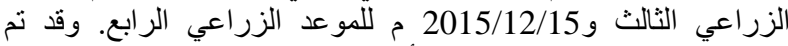

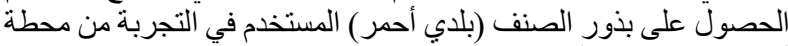

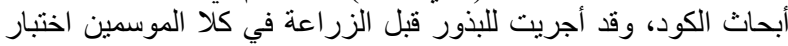

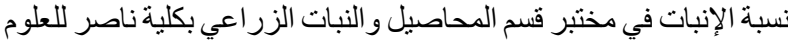

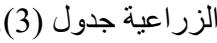

\begin{tabular}{|c|c|c|c|c|c|c|c|c|c|c|}
\hline \multicolumn{5}{|c|}{ الموسم الزراعي الثاني 2015} & \multicolumn{5}{|c|}{ الموسم الزراعي الأول 2014} & \multirow[t]{3}{*}{ الموسم } \\
\hline \multirow{2}{*}{ (الأمطار } & \multirow{2}{*}{ الرطوبة النسبية\%\% } & \multicolumn{3}{|c|}{ درجة الحرارة (م) } & \multirow{2}{*}{ الأمطار } & \multirow{2}{*}{ الرطوبة النسبية\%\% } & \multicolumn{3}{|c|}{ درجة الحرارة (مُ") } & \\
\hline & & المتوسط & الصغرى & العظمى & & & المتوسط & الصغرى & 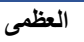 & \\
\hline 3.0 & 75.80 & 34.6 & 29.4 & 39.8 & 5.0 & 75.70 & 33 & 28 & 38 & أغسطس \\
\hline 8.0 & 76.20 & 34.7 & 30.3 & 39.1 & 2.0 & 45.10 & 32 & 27 & 37 & سبتمبر \\
\hline 3.0 & 79.30 & 32.35 & 26.5 & 38.2 & 4.0 & 78.10 & 28 & 23 & 33 & أكتوبر \\
\hline 0.0 & 83.30 & 30.25 & 25.3 & 35.2 & 0.7 & 81.20 & 25.5 & 21 & 30 & نوفمبر \\
\hline 4.0 & 86.20 & 25.85 & 21.5 & 30.2 & 0.3 & 85.30 & 23 & 19 & 27 & ديسمبر \\
\hline
\end{tabular}

جدول (4): المعدل الثهري لارجة الحرارة والرطوبة النسبية والأمطار خلال الموسمين الزراعيين أغسطس / ديسمبر 2014 و2015م 


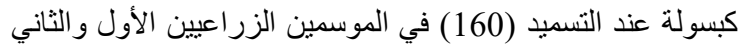

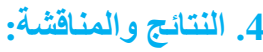

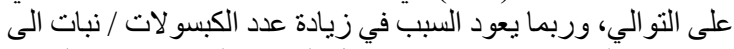
زيادة عدد الفروع / نبات وزيادة طول المنيط المنطة الثمرية، و هذه النتيجة

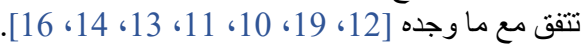

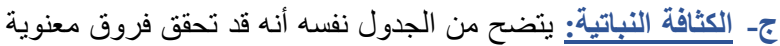

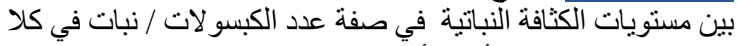

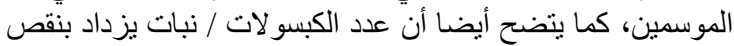

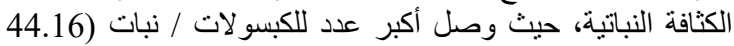

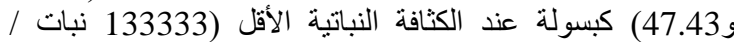

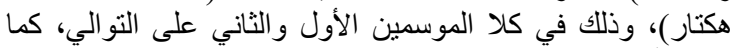

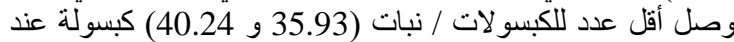

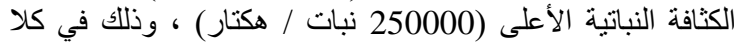

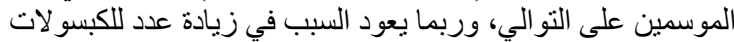

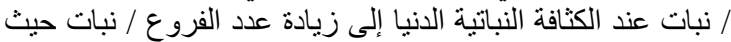

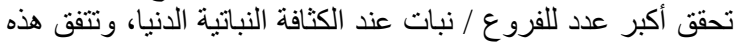

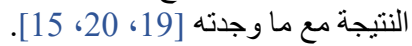

1.4. عدد الكبسولات / نبات (كبسولة):

أ- مواعيد الزراعة: يتضح من جدول (5) أنه قد تحققت فروق معنوية

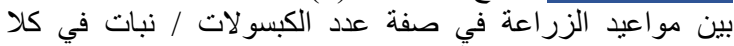

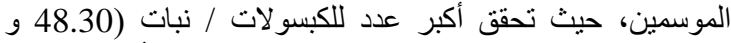

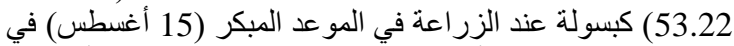

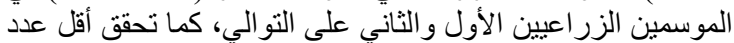

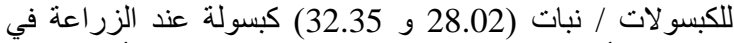

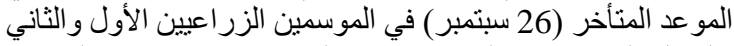

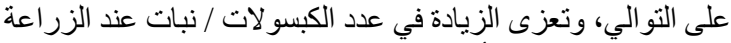

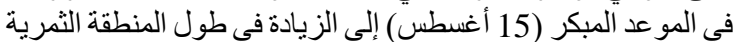

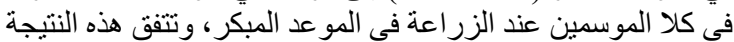

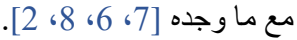

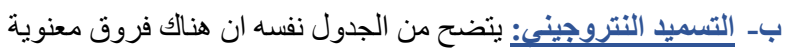

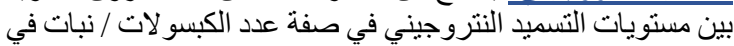
كلا الموسمين، حيث تحقق أكبر عدد للكبسو لات (46.22 و 50.72)

جدول (5): تأثير الكثافة النباتية والتسميد النتروجيني ومواعيد الزراعة على عدد الكبسولات / نبات (كبسولة) للموسمين 2014 و2015م

\begin{tabular}{|c|c|c|c|c|c|c|c|c|c|c|c|}
\hline & \multicolumn{4}{|c|}{ الموسم الزراعي الثاني 2015 م } & \multicolumn{5}{|c|}{ الموسم الزراعي الأول 2014 م } & \multirow{3}{*}{ (كجم/ هكتار) } & \multirow{3}{*}{ الكثافة الثباتية (نبات/ } \\
\hline \multicolumn{5}{|c|}{ مواعيد الزراعة } & & & 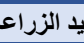 & & & & \\
\hline المتوسط & سبتمبر 26 & سبتمبر 12 & أغسطس & أغسطس & المتوسط & سبتمبر 26 & سبتمبر 12 & أغطس 29 & أغسطس & & \\
\hline 42.77 & 35.10 & 40.50 & 45.20 & 50.30 & 41.42 & 38.10 & 40.20 & 42.30 & 45.10 & صفر & \multirow{4}{*}{133333} \\
\hline 47.30 & 40.50 & 45.30 & 50.20 & 53.20 & 43.79 & 40.30 & 42.10 & 45.20 & 48.30 & 80 & \\
\hline 48.92 & 48.10 & 40.20 & 50.30 & 55.10 & 45.02 & 41.20 & 43.30 & 46.10 & 49.50 & 120 & \\
\hline 50.72 & 45.30 & 50.10 & 53.20 & 54.30 & 46.22 & 42.30 & 45.10 & 47.20 & 50.30 & 160 & \\
\hline 47.43 & 42.25 & 44.52 & 49.20 & 53.22 & 44.16 & 40.47 & 42.67 & 45.20 & 48.30 & & المتوسط \\
\hline 41.72 & 37.10 & 40.30 & 43.20 & 46.30 & 38.67 & 34.30 & 37.10 & 40.20 & 43.10 & صفر & \multirow{4}{*}{222222} \\
\hline 43.90 & 40.20 & 42.10 & 45.2 & 48.10 & 41.17 & 37.10 & 40.30 & 42.10 & 44.20 & 80 & \\
\hline 44.35 & 40.90 & 42.20 & 45.10 & 49.20 & 43.85 & 40.10 & 42.50 & 45.30 & 43.50 & 120 & \\
\hline 48.72 & 44.30 & 47.10 & 50.20 & 53.30 & 46.17 & 42.20 & 45.10 & 47.10 & 42.10 & 160 & \\
\hline 44.67 & 40.62 & 42.92 & 45.92 & 49.22 & 41.64 & 38.42 & 41.25 & 43.67 & 43.22 & & المتوسط \\
\hline 35.20 & 29.10 & 32.50 & 37.20 & 42.10 & 27.10 & 16.4 & 21.50 & 30.20 & 40.30 & صفر & \multirow{4}{*}{250000} \\
\hline 37.92 & 30.10 & 35.30 & 40.10 & 46.20 & 35.22 & 25.30 & 30.10 & 40.20 & 41.30 & 80 & \\
\hline 44.17 & 37.10 & 40.30 & 47.2 & 52.10 & 36.70 & 30.10 & 34.20 & 40.30 & 42.20 & 120 & \\
\hline 43.67 & 33.10 & 40.30 & 48.20 & 53.10 & 44.72 & 40.30 & 45.20 & 50.30 & 43.10 & 160 & \\
\hline 40.24 & 32.35 & 37.10 & 43.17 & 48.37 & 35.93 & 28.02 & 32.75 & 40.25 & 41.72 & & المتوسط \\
\hline \multicolumn{5}{|c|}{0.30} & \multicolumn{5}{|c|}{1.50} & الكثافة النباتية & \multirow{3}{*}{ أقل فرت معنوي عـ مند } \\
\hline \multicolumn{5}{|c|}{1.60} & \multicolumn{5}{|c|}{0.50} & التسميد النتروجيني & \\
\hline \multicolumn{5}{|c|}{0.60} & \multicolumn{5}{|c|}{1.30} & مواعيد الزراعة & \\
\hline
\end{tabular}

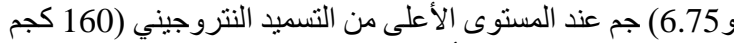

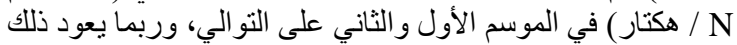

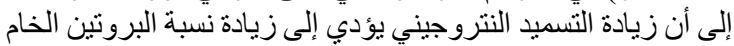

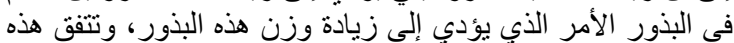

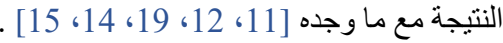

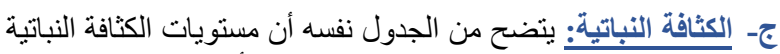

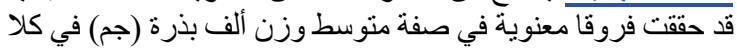

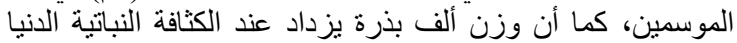

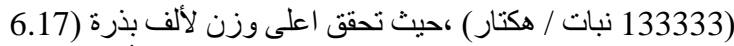

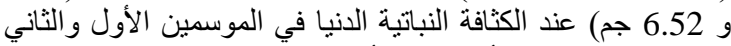

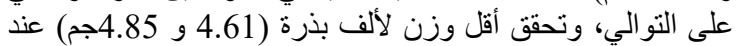

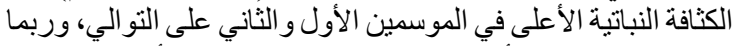

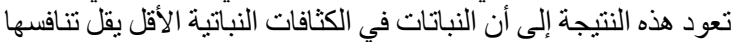

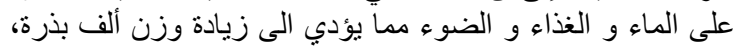

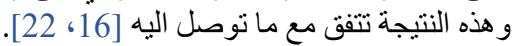

2.4. وزن ألف بذره (جم):

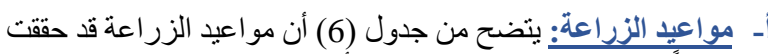

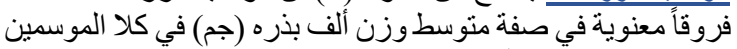

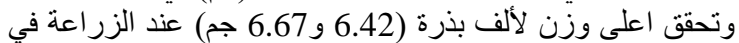

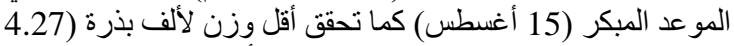

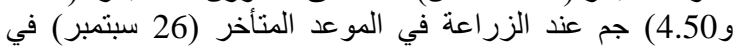

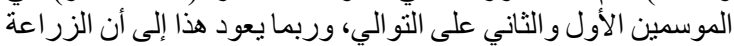

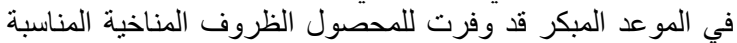

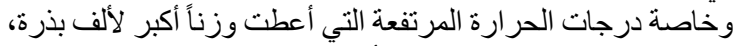

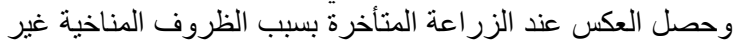

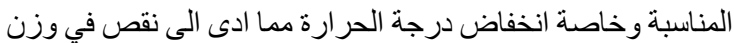

$$
\text { ألف بذرة، وتتفق هذه النتيجة مع ما وجده [7هة [7، 6]. }
$$

ب- التسميد النتروجيني: يتضح من الجدول نفسه أن مستويات التسميد

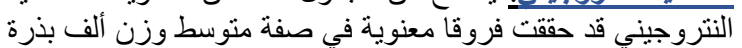

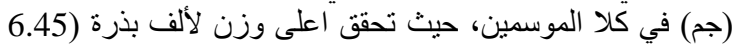


جدول (6): تأثير الكثافة النباتية والتسميد النتروجيني ومواعيد الزراعة على وزن ألف بذرة (جم) للموسمين 2014 و2015م

\begin{tabular}{|c|c|c|c|c|c|c|c|c|c|c|c|}
\hline \multicolumn{6}{|c|}{ الموسم الزراعي الثاني 2015 م } & \multicolumn{4}{|c|}{ الموسم الزراعي الأول 2014 م } & \multirow{3}{*}{ (التسميد (الثتروجيني } & \multirow{3}{*}{ الكثافة النباتية (نبات/ } \\
\hline \multicolumn{6}{|c|}{ مواعيد الزراعة } & \multicolumn{4}{|c|}{ مواعيد الزراعة } & & \\
\hline المتوسط & سبتمبر 26 & سبتمبر 12 & أغسطس & أغسطس & المتوسط & سبتمبر 26 & سبتمبر 12 & أغسطس & أغسطس & & \\
\hline 6.35 & 6.20 & 6.30 & 6.40 & 6.50 & 5.87 & 5.70 & 5.80 & 5.90 & 6.10 & صفر & \multirow{4}{*}{133333} \\
\hline 6.45 & 6.30 & 6.40 & 6.50 & 6.60 & 6.12 & 5.90 & 6.10 & 6.20 & 6.30 & 80 & \\
\hline 6.55 & 6.40 & 6.50 & 6.60 & 6.70 & 6.27 & 6.10 & 6.20 & 6.30 & 6.50 & 120 & \\
\hline 6.75 & 6.60 & 6.70 & 6.80 & 6.90 & 6.4 & 6.20 & 6.30 & 6.50 & 6.80 & 160 & \\
\hline 6.52 & 6.37 & 6.47 & 6.57 & 6.67 & 6.17 & 5.97 & 6.10 & 6.22 & 6.42 & & المتوسط \\
\hline 5.27 & 5.10 & 5.20 & 5.30 & 5.50 & 5.00 & 4.80 & 4.90 & 5.10 & 5.20 & صفر & \multirow{4}{*}{222222} \\
\hline 5.45 & 5.30 & 5.40 & 5.50 & 5.60 & 5.17 & 5.00 & 5.10 & 5.20 & 5.40 & 80 & \\
\hline 5.65 & 5.50 & 5.60 & 5.70 & 5.80 & 5.40 & 5.20 & 5.30 & 5.50 & 5.60 & 120 & \\
\hline 5.80 & 5.60 & 5.70 & 5.90 & 6.00 & 5.67 & 5.30 & 5.70 & 5.80 & 5.90 & 160 & \\
\hline 5.54 & 5.37 & 5.47 & 5.60 & 5.72 & 5.31 & 5.07 & 5.25 & 5.40 & 5.52 & & المتوسط \\
\hline 5.35 & 4.30 & 5.60 & 5.70 & 5.80 & 4.60 & 4.00 & 4.50 & 4.90 & 5.00 & صفر & \multirow{4}{*}{250000} \\
\hline 4.80 & 4.50 & 4.80 & 4.90 & 5.00 & 4.75 & 4.60 & 4.70 & 4.80 & 4.90 & 80 & \\
\hline 4.55 & 4.70 & 4.40 & 4.50 & 4.60 & 4.37 & 4.20 & 4.4 & 4.40 & 4.50 & 120 & \\
\hline 4.72 & 4.50 & 4.70 & 4.80 & 4.90 & 4.74 & 4.20 & 4.40 & 4.20 & 4.30 & 160 & \\
\hline 4.85 & 4.50 & 4.87 & 4.97 & 5.07 & 4.61 & 4.27 & 5.47 & 4.57 & 4.67 & & المتوسط \\
\hline \multicolumn{6}{|c|}{0.30} & \multicolumn{4}{|c|}{0.20} & الكثافة النباتية & \multirow{3}{*}{ 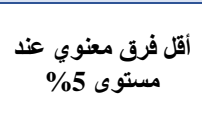 } \\
\hline \multicolumn{6}{|c|}{0.40} & \multicolumn{4}{|c|}{0.50} & التسميد النتروجيني & \\
\hline \multicolumn{6}{|c|}{0.25} & \multicolumn{4}{|c|}{0.30} & مواعيد الزراعة & \\
\hline
\end{tabular}

الموسمين الأول و الثاني على التو الي، وربما يعود السبب في زيادة النيان

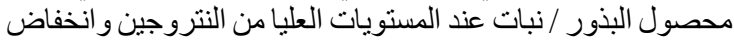

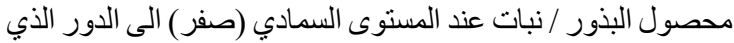

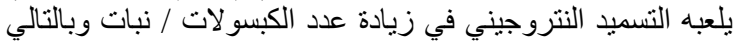

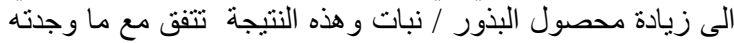

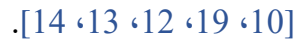

ج- الكثافة النباتية: يتضح من الجدول نفسه أن مستويات الكثافة النباتية،

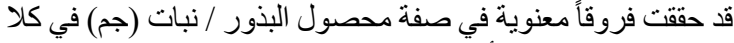

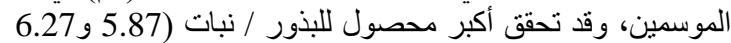

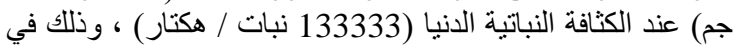

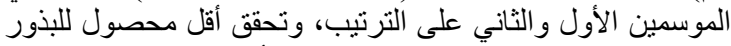

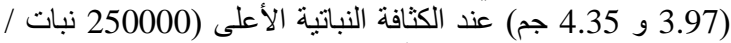

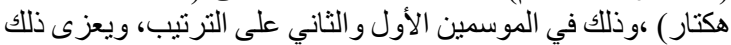

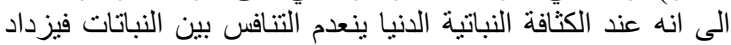

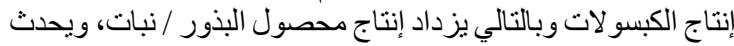

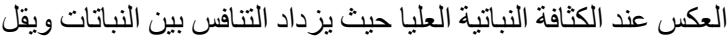

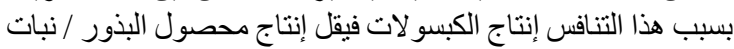
وتتفق هذه النتيجة مع ما نوصل إلتباحل إليه فئل [20، 21، 22، 19، 15، 16].
3.4. محصول البذور / نبات (جم):

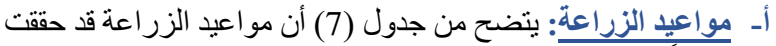

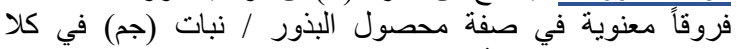

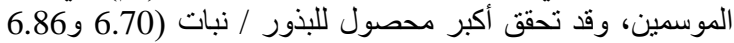

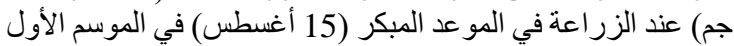

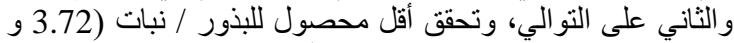

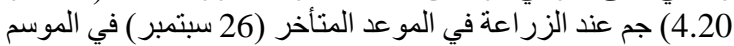

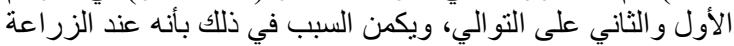

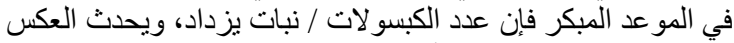

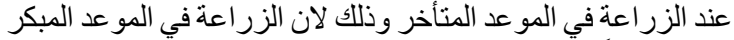

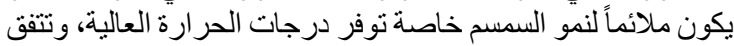

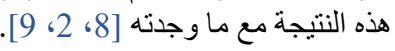

ب- التسميد النتروجيني: يتضح من الجدول نفسه أن مستويات التسميد

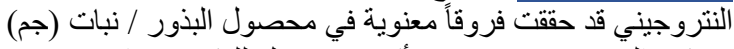

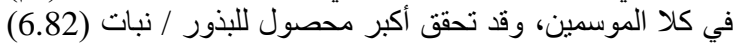

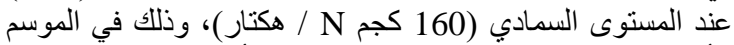

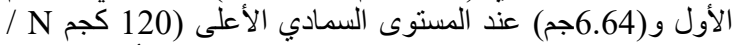

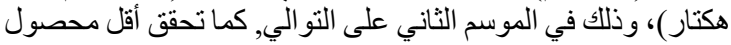

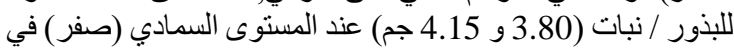

جدول (7): تأثير الكثافة النباتية والتسميد النتروجيني ومواعيد الزراعة على محصول البذور / نبات (جم) للموسمين 2014 و2015م:

\begin{tabular}{|c|c|c|c|c|c|c|c|c|c|c|c|}
\hline \multicolumn{5}{|c|}{ الموسم الزراعي الثاني 2015 م } & \multicolumn{5}{|c|}{ الموسم الزراعي الأول 2014 م } & \multirow{3}{*}{ (التسميد/ هتثتروجيني } & \multirow{3}{*}{ (الكثاتة هكتار) } \\
\hline \multicolumn{5}{|c|}{ مواعيد الزراعة } & \multicolumn{5}{|c|}{ مواعيد الزراعة } & & \\
\hline المتوسط & سبتمبر 26 & سبتمبر 12 & أغسطس & أغسطس & المتوسط & سبتمبر 26 & سبتمبر 12 & أغسطس & أغسطس & & \\
\hline 5.77 & 4.90 & 5.80 & 5.90 & 6.50 & 4.72 & 3.30 & 4.20 & 5.30 & 6.10 & صفر & \\
\hline 6.32 & 5.20 & 6.60 & 6.70 & 6.80 & 5.62 & 4.20 & 5.40 & 6.10 & 6.80 & 80 & 123233 \\
\hline 6.64 & 5.90 & 6.80 & 6.90 & 6.95 & 6.32 & 5.10 & 6.50 & 6.80 & 6.90 & 120 & 133333 \\
\hline 6.37 & 5.30 & 6.20 & 6.80 & 7.20 & 6.82 & 6.60 & 6.80 & 6.90 & 7.00 & 160 & \\
\hline 6.27 & 5.32 & 6.35 & 6.57 & 6.86 & 5.87 & 4.80 & 5.72 & 6.27 & 6.70 & & المتوسط \\
\hline 4.82 & 4.10 & 4.9 & 5.00 & 5.30 & 4.67 & 3.50 & 4.90 & 5.10 & 5.20 & صفر & \\
\hline 4.95 & 4.20 & 5.00 & 5.20 & 5.40 & 5.32 & 4.90 & 5.00 & 5.30 & 6.10 & 80 & 222222 \\
\hline 5.30 & 4.40 & 5.60 & 5.60 & 5.60 & 5.57 & 5.00 & 5.60 & 5.50 & 6.20 & 120 & \\
\hline
\end{tabular}




\begin{tabular}{|c|c|c|c|c|c|c|c|c|c|c|c|}
\hline 5.47 & 4.60 & 5.70 & 5.80 & 5.80 & 5.92 & 5.70 & 5.80 & 5.90 & 6.30 & 160 & \\
\hline 5.13 & 4.32 & 5.30 & 5.40 & 5.52 & 5.37 & 4.77 & 5.32 & 5.45 & 5.95 & & المتوسط \\
\hline 4.15 & 4.00 & 4.10 & 4.20 & 4.30 & 3.80 & 3.40 & 3.50 & 4.20 & 4.10 & صفر & \multirow{4}{*}{250000} \\
\hline 4.25 & 4.10 & 4.20 & 4.30 & 4.40 & 3.87 & 3.60 & 3.80 & 3.90 & 4.20 & 80 & \\
\hline 4.35 & 4.20 & 4.30 & 4.40 & 4.50 & 3.92 & 3.70 & 3.80 & 3.90 & 4.30 & 120 & \\
\hline 4.65 & 4.50 & 4.60 & 4.70 & 4.80 & 4.30 & 4.20 & 4.30 & 4.20 & 4.50 & 160 & \\
\hline 4.35 & 4.20 & 4.30 & 4.40 & 4.50 & 3.97 & 3.72 & 3.85 & 4.05 & 4.27 & & المتوسط \\
\hline \multicolumn{5}{|c|}{0.03} & \multicolumn{5}{|c|}{0.20} & الكثافة النباتية & \multirow{3}{*}{ 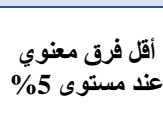 } \\
\hline \multicolumn{5}{|c|}{0.03} & \multicolumn{5}{|c|}{0.10} & لتسميد النتروجيني & \\
\hline \multicolumn{5}{|c|}{0.02} & \multicolumn{5}{|c|}{0.30} & مواعيد الزراعة & \\
\hline
\end{tabular}

على التو الي، ويعود ذلك للاور الذي يقوم به عنصر النتروجين سواء

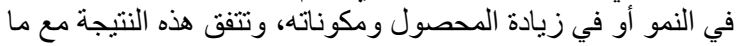
توصل اليه [16، 15] فيادة.

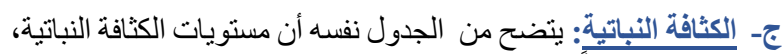

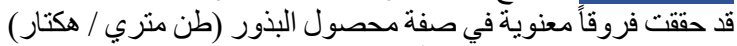

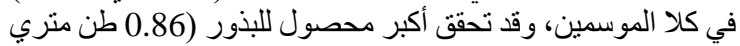

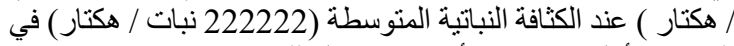

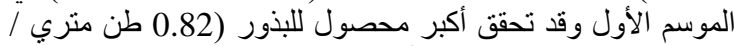

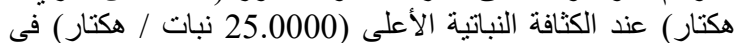
الموسم الثاني, كما تحقق أقل محصول للألذانور (0.64 و 0.70 طن متري / هكتار) عند الكثافة النباتية الدنيا (133333 نبات الكات / هكتار) في الموسمين الأول و الثاني على التو الي، بسبب أنيا أنه عند الكثافة النباتية

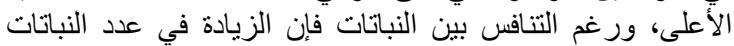

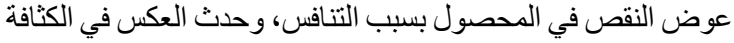

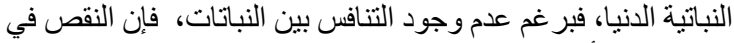

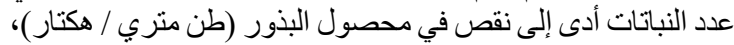

و هذه النتيجة تتفق مع ما توصل إلئه إليه [17، 16].
4.4. محصول البذور (طن متري/ هكتّر):

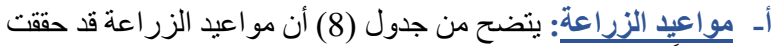

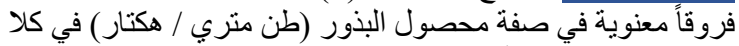

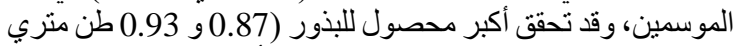

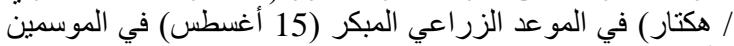

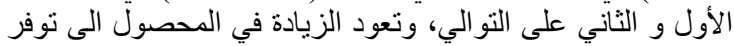

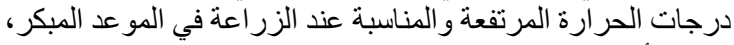

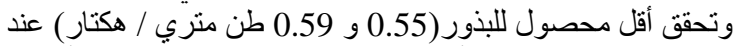

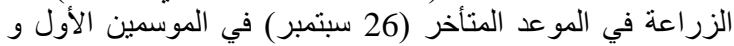

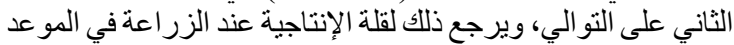

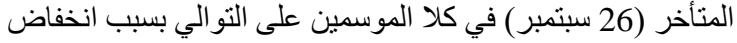

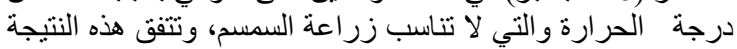

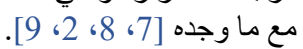

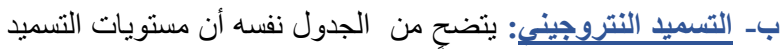

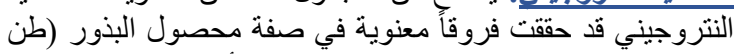

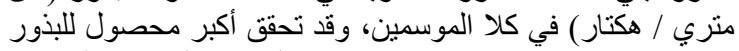

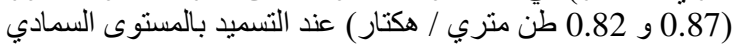

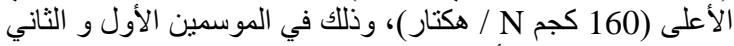

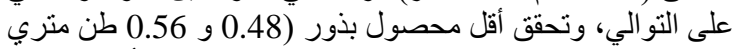
/ هكتار) عند المستوى السمادي (صفر) في الموسمين الأول و الثاني

جدول (8): تأثير الكثافة النباتية والتسميد النتروجيني ومواعيد الزراعة على محصول البذور / نبات (طن متري / هكتار) للموسمين 2014 و2015م

\begin{tabular}{|c|c|c|c|c|c|c|c|c|c|c|c|}
\hline \multicolumn{6}{|c|}{ الموسم الزراعي الثاني 2015 م } & \multicolumn{4}{|c|}{ الموسم الزراعي الأول 2014 م } & \multirow{3}{*}{ (كجميد / هكترار) } & \multirow{3}{*}{ الكثافة النباتية (نبات/ } \\
\hline \multicolumn{6}{|c|}{ مواعيد الزراعة } & & & 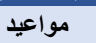 & & & \\
\hline المتوسط & سبتمبر 26 & سبتمبر 12 & أغسطس & أغسطس 15 & المتوسط & سبتمبر 26 & سبتمبر 12 & أغطس 29 & أغسطس 15 & & \\
\hline 0.56 & 0.45 & 0.50 & 0.60 & 0.70 & 0.48 & 0.40 & 0.43 & 0.50 & 0.60 & صفر & \multirow{4}{*}{133333} \\
\hline 0.66 & 0.55 & 0.60 & 0.70 & 0.80 & 0.61 & 0.50 & 0.60 & 0.65 & 0.70 & 80 & \\
\hline 0.75 & 0.60 & 0.70 & 0.80 & 0.90 & 0.69 & 0.60 & 0.65 & 0.70 & 0.80 & 120 & \\
\hline 0.85 & 0.75 & 0.80 & 0.90 & 0.95 & 0.77 & 0.70 & 0.75 & 0.80 & 0.85 & 160 & \\
\hline 0.70 & 0.59 & 0.65 & 0.75 & 0.84 & 0.64 & 0.55 & 0.61 & 0.66 & 074 & & المتوسط \\
\hline 0.65 & 0.50 & 0.60 & 0.70 & 0.80 & 0.56 & 0.45 & 0.50 & 0.60 & 0.70 & صفر & \multirow{4}{*}{222222} \\
\hline 0.74 & 0.60 & 0.70 & 0.80 & 0.85 & 0.65 & 0.55 & 0.60 & 0.70 & 0.75 & 80 & \\
\hline 0.82 & 0.75 & 0.80 & 0.85 & 0.90 & 0.71 & 0.60 & 0.70 & 0.75 & 0.80 & 120 & \\
\hline 0.87 & 0.80 & 0.85 & 0.90 & 0.95 & 0.79 & 0.70 & 0.75 & 0.80 & 0.90 & 160 & \\
\hline 0.77 & 0.66 & 0.74 & 0.84 & 0.87 & 0.86 & 0.57 & 0.64 & 0.71 & 0.79 & & المتوسط \\
\hline 0.75 & 0.60 & 0.70 & 0.80 & 0.90 & 0.61 & 0.50 & 0.55 & 0.60 & 0.80 & صفر & \multirow{4}{*}{250000} \\
\hline 0.83 & 0.70 & 0.80 & 0.90 & 0.93 & 0.74 & 0.60 & 0.70 & 0.80 & 0.85 & 80 & \\
\hline 0.89 & 0.80 & 0.90 & 0.93 & 0.94 & 0.81 & 0.70 & 0.80 & 0.85 & 0.90 & 120 & \\
\hline 0.82 & 0.60 & 0.80 & 0.94 & 0.95 & 0.87 & 0.80 & 0.85 & 0.90 & 0.95 & 160 & \\
\hline 0.82 & 0.67 & 0.80 & 0.89 & 0.93 & 0.76 & 0.65 & 0.72 & 0.79 & 0.87 & & المتوسط \\
\hline \multicolumn{6}{|c|}{0.04} & \multicolumn{4}{|c|}{0.03} & الكثافة النباتية & \multirow{3}{*}{ 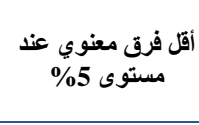 } \\
\hline \multicolumn{6}{|c|}{0.03} & \multicolumn{4}{|c|}{0.02} & التسميد النتروجيني & \\
\hline \multicolumn{6}{|c|}{0.02} & \multicolumn{4}{|c|}{0.03} & مواعيد الزراعة & \\
\hline
\end{tabular}




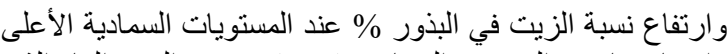

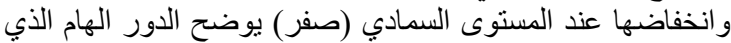

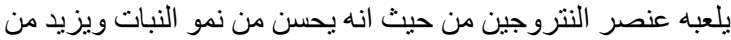

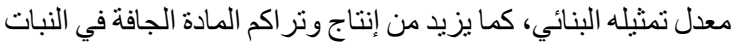

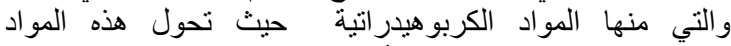

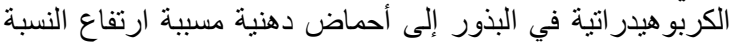

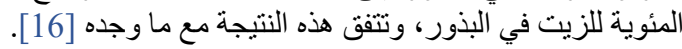

ج- الكثافة النباتية: يلاحظ من الجدول نفسه أن مستويات الكثافة النباتية،

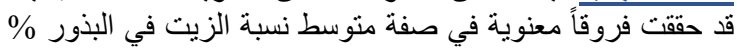

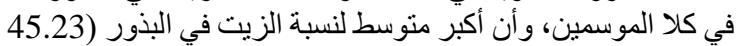

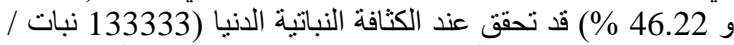

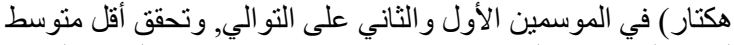

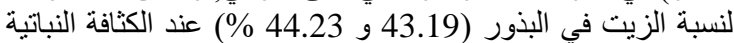

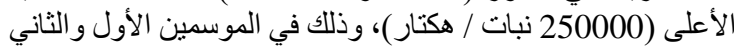

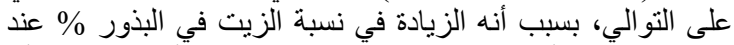

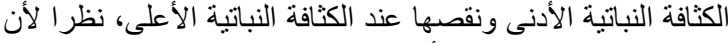

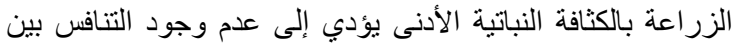

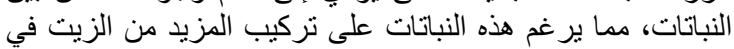

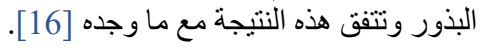

5.4. نسبة الزيت في البذور \%

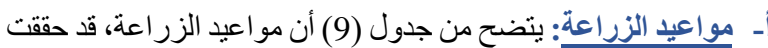

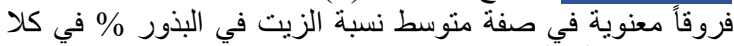

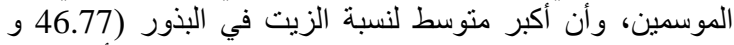

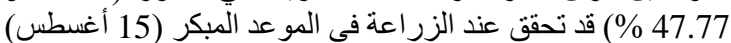

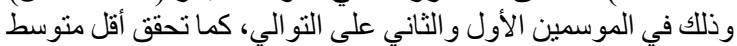

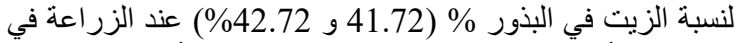
المو عد المتأخر (26 سبتمبر ) وذلك في الموسمين الأول و الثناني على في الزي

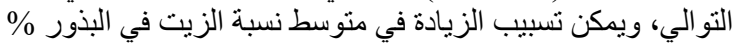

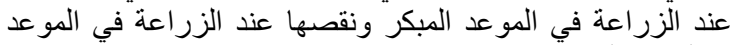

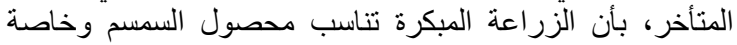

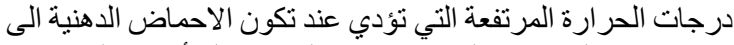

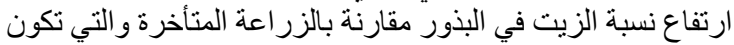
الحر ارة عندها قد انخفضت، ونتفق هذه النتيجة مع ما وجده [2، 9)

ب- التسميا النتروجيني: يتضح من الجدول نفسه أن مستويات التسميد

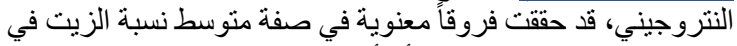

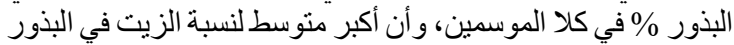

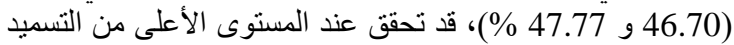

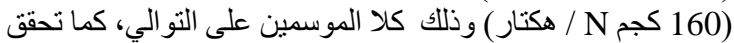

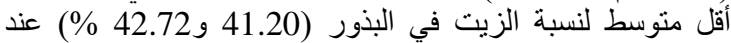
المستوى السمادي(صفر) في الموسمين الأول و الثاني على التور الئ،

جدول (9): تأثير الكثافة التباتية والتسميد النتروجيني ومواعيد الزراعة على نسبة الزيت في البذور \% في الموسمين 2014 و2015م

\begin{tabular}{|c|c|c|c|c|c|c|c|c|c|c|c|}
\hline \multicolumn{5}{|c|}{ الموسم الزراعي الثاني 2015 م } & \multicolumn{5}{|c|}{ الموسم الزراعي الأول 2014 م } & \multirow{3}{*}{ التسميد (التتروجيني } & \multirow{3}{*}{ الكثافة الثباتية (نبات/ } \\
\hline \multicolumn{5}{|c|}{ مواعيد الزراعة } & \multicolumn{5}{|c|}{ مواعيد الزراعة } & & \\
\hline المتوسط & سبتمبر 26 & سبتمبر 12 & أغسطس & أغسطس & المتوسط & سبتمبر 26 & سبتمبر 12 & أغسطس & أغسطس 15 & & \\
\hline 44.72 & 43.20 & 44.10 & 45.30 & 46.30 & 43.70 & 42.20 & 43.30 & 44.20 & 45.10 & صفر & \multirow{4}{*}{133333} \\
\hline 45.70 & 44.20 & 45.30 & 46.10 & 47.20 & 44.72 & 43.30 & 44.20 & 45.10 & 46.30 & 80 & \\
\hline 46.70 & 45.30 & 46.10 & 47.30 & 48.10 & 45.82 & 44.30 & 45.20 & 46.30 & 47.50 & 120 & \\
\hline 47.77 & 46.20 & 47.30 & 48.10 & 49.50 & 46.70 & 45.30 & 46.20 & 47.10 & 48.20 & 160 & \\
\hline 46.22 & 44.72 & 45.70 & 46.70 & 47.77 & 45.23 & 43.77 & 44.72 & 45.67 & 46.77 & & المتوسط \\
\hline 43.70 & 42.30 & 43.20 & 44.10 & 45.20 & 42.72 & 41.30 & 42.10 & 43.20 & 44.30 & صفر & \multirow{4}{*}{222222} \\
\hline 44.72 & 43.20 & 44.10 & 45.30 & 46.30 & 43.67 & 42.20 & 43.30 & 44.10 & 45.10 & 80 & \\
\hline 45.75 & 44.30 & 45.10 & 46.30 & 47.30 & 44.70 & 43.30 & 44.20 & 45.10 & 46.20 & 120 & \\
\hline 46.67 & 45.30 & 46.10 & 47.20 & 48.10 & 45.67 & 44.20 & 45.30 & 46.10 & 47.10 & 160 & \\
\hline 45.21 & 43.77 & 44.62 & 45.72 & 46.72 & 44.19 & 42.75 & 43.72 & 44.62 & 45.67 & & المتوسط \\
\hline 42.72 & 41.30 & 42.10 & 43.20 & 44.30 & 41.20 & 40.20 & 41.30 & 42.10 & 43.20 & صفر & \multirow{4}{*}{250000} \\
\hline 43.72 & 42.20 & 43.30 & 44.30 & 45.10 & 42.67 & 41.30 & 42.20 & 43.10 & 44.10 & 80 & \\
\hline 44.80 & 43.30 & 44.20 & 45.40 & 46.30 & 43.72 & 42.30 & 43.10 & 44.20 & 45.30 & 120 & \\
\hline 45.70 & 44.10 & 45.30 & 46.30 & 47.10 & 44.67 & 43.10 & 44.20 & 45.30 & 46.10 & 160 & \\
\hline 44.23 & 42.72 & 43.72 & 44.80 & 45.70 & 43.19 & 41.72 & 42.70 & 43.67 & 44.67 & & المتوسط \\
\hline \multicolumn{5}{|c|}{0.90} & \multicolumn{5}{|c|}{1.03} & الكثافة النباتية & \multirow{3}{*}{ 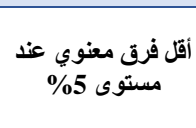 } \\
\hline \multicolumn{5}{|c|}{0.60} & \multicolumn{5}{|c|}{1.02} & التسميد النتروجيني & \\
\hline \multicolumn{5}{|c|}{0.50} & \multicolumn{5}{|c|}{1.01} & مواعيد الزراعة & \\
\hline
\end{tabular}

ب- التسميا النتروجيني: يتضح من الجدول نفسه أن مستويات التسميد

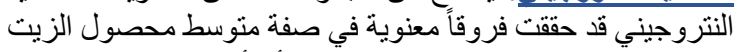

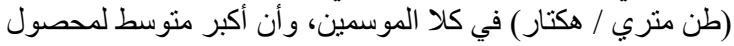

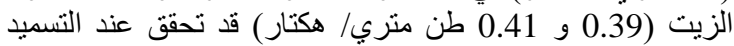

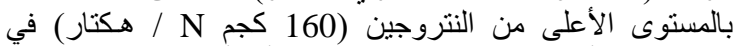

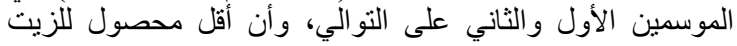

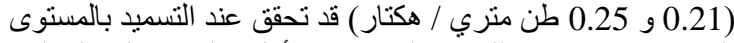

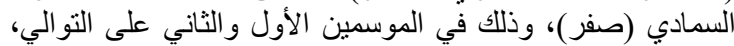

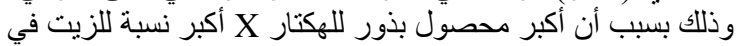

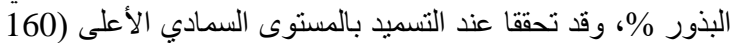

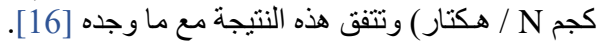

6.4. محصول الزيت (طن مثري/ هكتار):

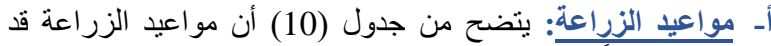

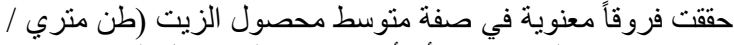

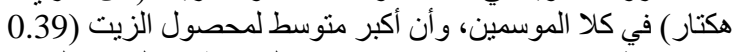

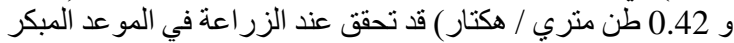

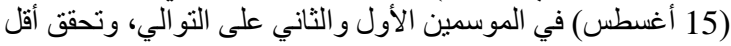

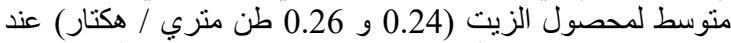

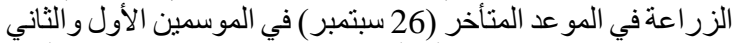

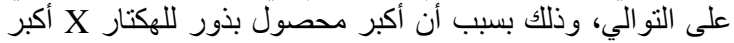

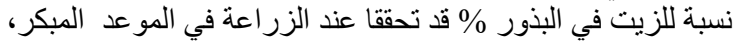

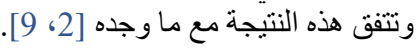




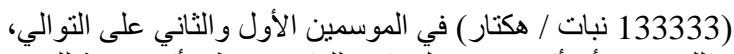

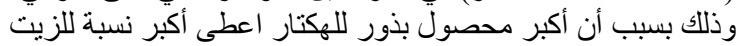

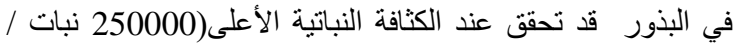

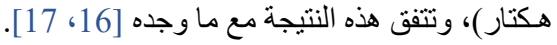

ج- الكثافة النباتية: ينضح من الجدول نفسه أن مسنويات الكثافة النباتية،

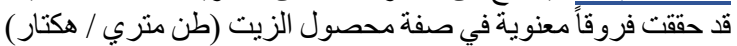

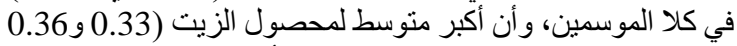

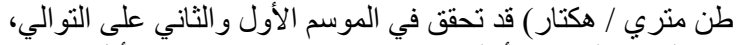

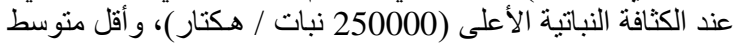
لمحصول الزيت (0.29 و0.32 طن متري / هكتار ) عند الكثافة الدنيا

جدول (10): تأثير الكثافة النباتية والتسميد النتروجيني ومواعيد الزراعة على متوسط نسبة محصول الزيت (طن متري / هكتار) في الموسمين 2014

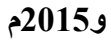

\begin{tabular}{|c|c|c|c|c|c|c|c|c|c|c|c|}
\hline \multicolumn{5}{|c|}{ الموسم الزراعي الثاني 2015 م } & \multicolumn{5}{|c|}{ الموسم الزراعي الأول 2014 م } & \multirow{3}{*}{ (كجم/ هكتار) } & \multirow{3}{*}{ (الكثافة النتباتية) (نبات/ } \\
\hline \multicolumn{5}{|c|}{ مواعيد الزراعة } & & & عيد الزراء & & & & \\
\hline المتوسط المت & 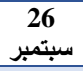 & سبتمبر 12 & أغسطس & أغسطس & المتوسط & $\begin{array}{l}26 \\
\end{array}$ & سبتمبر 12 & أغطس 29 & أغسطس & & \\
\hline 0.25 & 0.19 & 0.22 & 0.27 & 0.32 & 0.21 & 0.17 & 0.19 & 0.22 & 0.27 & صفر & \multirow{4}{*}{133333} \\
\hline 0.30 & 0.24 & 0.27 & 0.32 & 0.38 & 0.27 & 0.22 & 0.26 & 0.29 & 0.32 & 80 & \\
\hline 0.35 & 0.27 & 0.32 & 0.59 & 0.43 & 0.31 & 0.26 & 0.29 & 0.32 & 0.38 & 120 & \\
\hline 0.41 & 0.35 & 0.38 & 0.43 & 0.47 & 0.36 & 0.32 & 0.35 & 0.38 & 0.41 & 160 & \\
\hline 0.32 & 0.26 & 0.30 & 0.40 & 0.40 & 0.29 & 0.24 & 0.27 & 0.30 & 0.35 & & المتوسط \\
\hline 0.28 & 0.21 & 0.26 & 0.31 & 0.36 & 0.24 & 0.18 & 0.21 & 0.26 & 0.31 & صفر & \multirow{4}{*}{222222} \\
\hline 0.33 & 0.26 & 0.31 & 0.36 & 0.39 & 0.28 & 0.23 & 0.26 & 0.31 & 0.34 & 80 & \\
\hline 0.37 & 0.33 & 0.36 & 0.39 & 0.42 & 0.32 & 0.26 & 0.31 & 0.34 & 0.37 & 120 & \\
\hline 0.41 & 0.36 & 0.39 & 0.42 & 0.46 & 0.36 & 0.31 & 0.34 & 0.37 & 0.42 & 160 & \\
\hline 0.35 & 0.29 & 0.33 & 0.37 & 0.41 & 0.30 & 0.25 & 0.28 & 0.32 & 0.36 & & المتوسط \\
\hline 0.32 & 0.25 & 0.29 & 0.34 & 0.40 & 0.25 & 0.20 & 0.23 & 0.25 & 0.34 & صفر & \multirow{4}{*}{250000} \\
\hline 0.36 & 0.29 & 0.35 & 0.40 & 0.42 & 0.31 & 0.25 & 0.29 & 0.34 & 0.37 & 80 & \\
\hline 0.40 & 0.35 & 0.40 & 0.42 & 0.43 & 0.35 & 0.30 & 0.34 & 0.37 & 0.41 & 120 & \\
\hline 0.37 & 0.26 & 0.35 & 0.43 & 0.45 & 0.39 & 0.34 & 0.37 & 0.41 & 0.44 & 160 & \\
\hline 0.36 & 0.29 & 0.35 & 0.40 & 0.42 & 0.33 & 0.27 & 0.31 & 0.34 & 0.39 & & المتوسط \\
\hline \multicolumn{5}{|c|}{0.01} & \multicolumn{5}{|c|}{0.02} & الكثافة النباتية & \multirow{3}{*}{ أقل فرق معنوي عند } \\
\hline \multicolumn{5}{|c|}{0.01} & \multicolumn{5}{|c|}{0.01} & التسميد النتروجيني & \\
\hline \multicolumn{5}{|c|}{0.01} & \multicolumn{5}{|c|}{0.01} & مواعيد الزراعة & \\
\hline
\end{tabular}

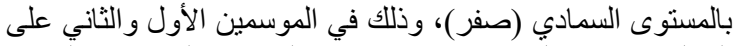

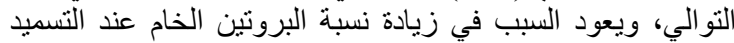

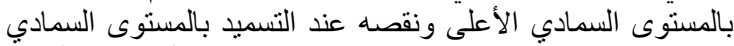

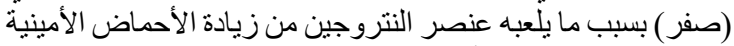

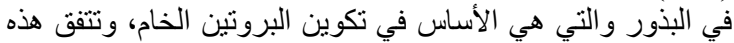

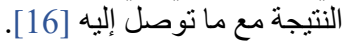

ج- الكثافة النباتية: يتضح من نفس الجدول فئدة أن مستويات الكثافة النباتية

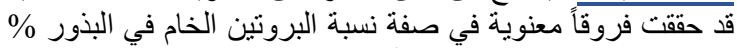

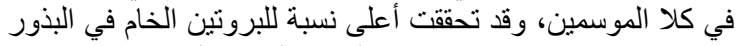

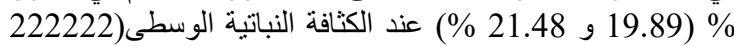

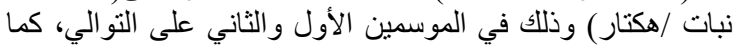
تحققت أقل نسبة للبروتين الخام في البذور (18.26 و 19.71 \% عند الكثافة النباتية الأعلى (250000 نبات النئ / هكتار ) وذلك في الموسم

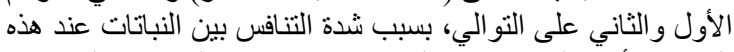

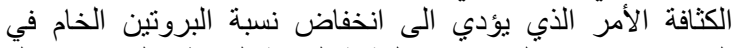

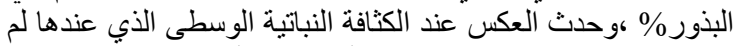

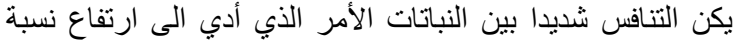

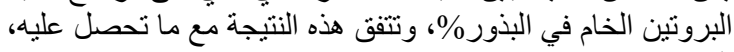

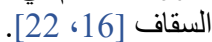

7.4. نسبة البروتين الخام في البذور \%\%

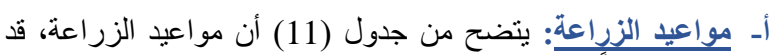

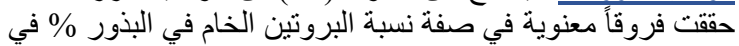

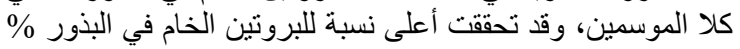

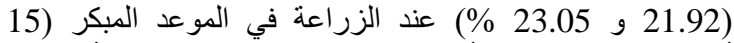

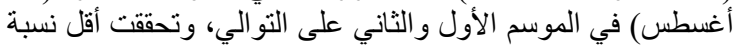

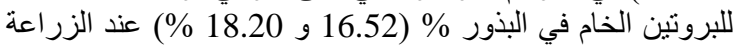

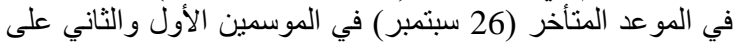

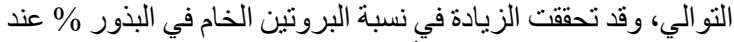

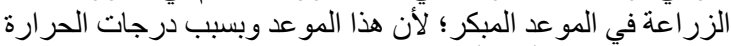

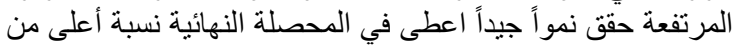

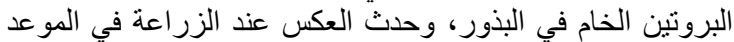

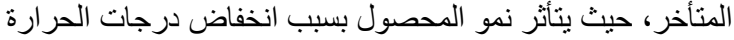

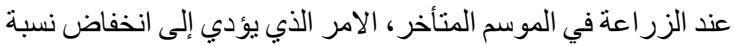

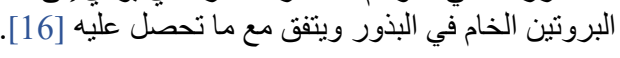

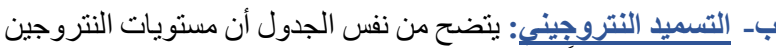

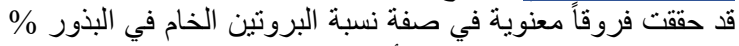

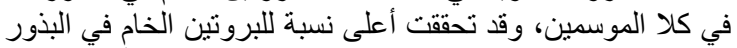

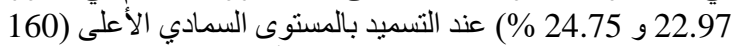
كجم N / هكتار )، وذللك في الموسمين الأول و الثاني على النى التو الي،

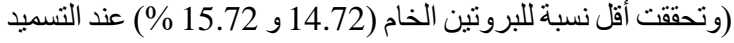


جدول (11): تأثير الكثافة النباتية والتسميد النتروجيني ومواعيد الزراعة على متوسط نسبة البروتين الخام في البذور \% في الموسمين 2014 و2015م

\begin{tabular}{|c|c|c|c|c|c|c|c|c|c|c|c|}
\hline \multicolumn{5}{|c|}{ الموسم الزراعي الثاني 2015 م } & \multicolumn{5}{|c|}{ الموسم الززراعي الأول 2014 م } & \multirow{3}{*}{ (كجم / هكتار) } & \multirow{3}{*}{ (كبات / هكتار) } \\
\hline \multicolumn{5}{|c|}{ مواعيد الزراعة } & & & بِّ الزراعا & & & & \\
\hline المتوسط & سبتمبر & سبتمبر 12 & أغسطس & أغسطس 15 & المتوسط & سبتمبر & سبتمبر 12 & أغسطس & أغسطس & & \\
\hline 18.72 & 17.30 & 18.10 & 19.20 & 20.30 & 17.20 & 15.30 & 16.20 & 18.10 & 19.20 & صفر & \multirow{4}{*}{133333} \\
\hline 19.70 & 18.20 & 19.30 & 20.10 & 21.20 & 18.25 & 16.20 & 17.30 & 19.20 & 20.30 & 80 & \\
\hline 20.72 & 19.30 & 20.10 & 21.20 & 22.30 & 19.27 & 17.10 & 18.20 & 20.30 & 21.50 & 120 & \\
\hline 22.72 & 21.30 & 22.10 & 23.20 & 24.30 & 21.25 & 19.20 & 20.30 & 22.40 & 23.10 & 160 & \\
\hline 20.46 & 19.02 & 19.90 & 20.92 & 22.02 & 18.99 & 16.95 & 18.00 & 20.00 & 21.02 & & المتوسط \\
\hline 17.67 & 16.10 & 17.20 & 18.30 & 19.10 & 15.95 & 14.20 & 15.10 & 16.20 & 18.30 & صفر & \multirow{4}{*}{222222} \\
\hline 20.72 & 19.30 & 20.10 & 21.20 & 22.30 & 18.97 & 17.30 & 18.20 & 19.30 & 21.10 & 80 & \\
\hline 22.77 & 21.30 & 22.20 & 23.10 & 24.50 & 21.67 & 20.10 & 21.30 & 22.10 & 23.20 & 120 & \\
\hline 24.75 & 23.30 & 24.30 & 25.10 & 26.30 & 22.97 & 21.30 & 22.30 & 23.20 & 25.10 & 160 & \\
\hline 21.48 & 20.00 & 20.95 & 21.92 & 23.05 & 19.89 & 18.22 & 19.22 & 20.20 & 21.92 & & المتوسط \\
\hline 15.72 & 14.20 & 15.30 & 16.10 & 17.30 & 14.72 & 13.30 & 14.10 & 15.20 & 16.30 & صفر & \multirow{4}{*}{250000} \\
\hline 18.72 & 17.20 & 18.30 & 19.10 & 20.30 & 17.72 & 16.30 & 17.10 & 18.30 & 19.20 & 80 & \\
\hline 20.72 & 19.30 & 20.10 & 21.20 & 22.30 & 18.95 & 17.20 & 18.10 & 19.20 & 21.30 & 120 & \\
\hline 23.70 & 22.10 & 23.30 & 24.10 & 25.30 & 21.67 & 19.30 & 20.10 & 23.20 & 24.10 & 160 & \\
\hline 19.71 & 18.20 & 19.25 & 20.12 & 21.30 & 18.26 & 16.52 & 17.35 & 18.97 & 20.22 & & المتوسط \\
\hline \multicolumn{5}{|c|}{0.74} & \multicolumn{5}{|c|}{0.70} & الكثافة النباتية & \multirow{3}{*}{ أقل فرق معنوى 5 } \\
\hline \multicolumn{5}{|c|}{0.50} & \multicolumn{5}{|c|}{0.60} & النتروجيني & \\
\hline \multicolumn{5}{|c|}{0.30} & \multicolumn{5}{|c|}{0.20} & مواعيد الزراعة & \\
\hline
\end{tabular}

محصول للبذور / هكتار X أكبر نسبة للبروتين الخام في البذور، الأنه

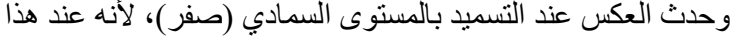

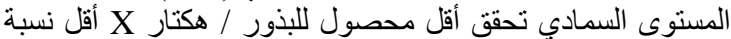

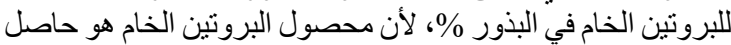

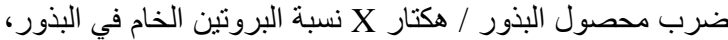

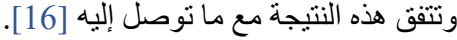

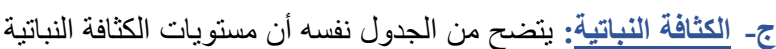

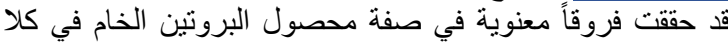

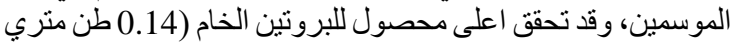

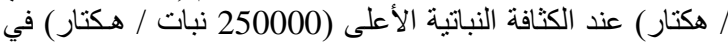

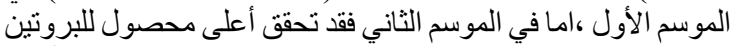

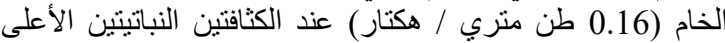

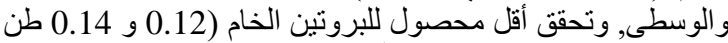

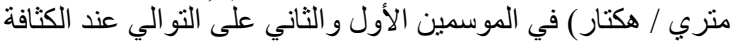

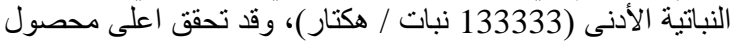

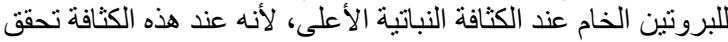

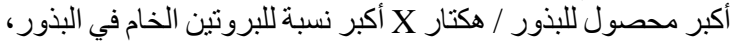

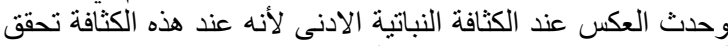

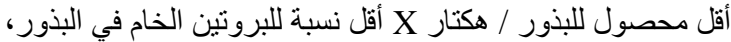

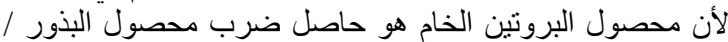

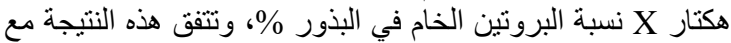

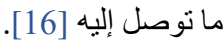

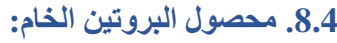

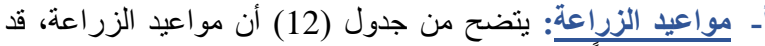

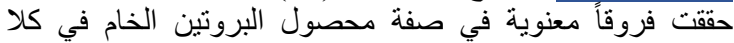

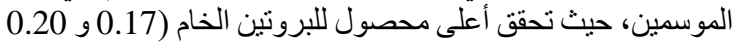

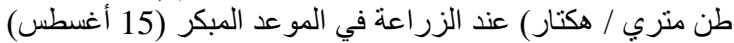

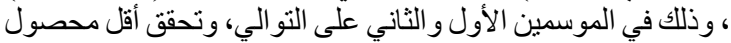

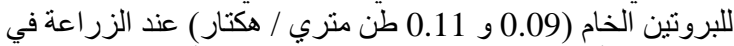

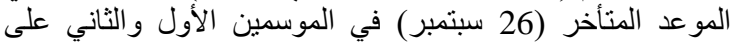

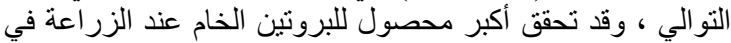

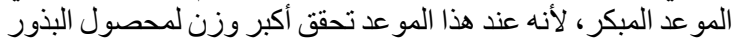

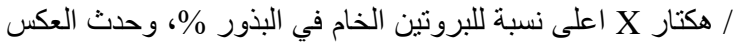

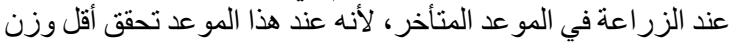

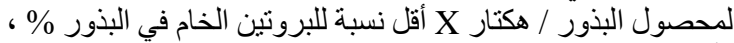

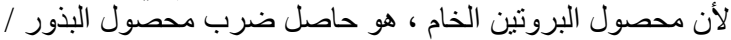

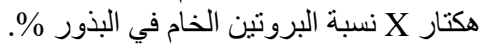

ب- التسميا النتروجيني: يتضح من الجدول نفسه أن مستويات التسميد

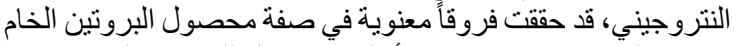

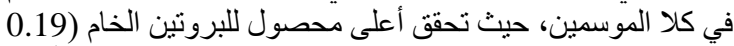

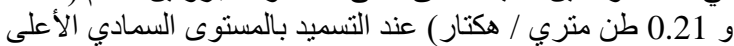

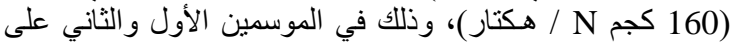

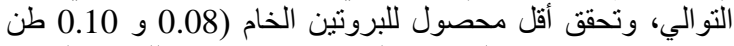

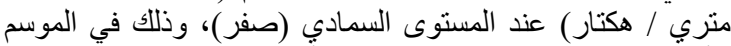

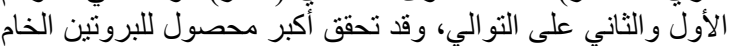
عند التسميد بالمستوى الأعلى لأنه عند هذا التهر المستوى تحقق أكبر

جدول (12): تأثير الكثافة النباتية والتسميد النتروجيني ومواعيد الزراعة على محصول البروتين الخام (طن متري / هكتار) في الموسمين 2014 و2015م

\begin{tabular}{|c|c|c|c|c|c|c|c|c|c|c|c|}
\hline \multicolumn{5}{|c|}{ الموسم الزراعي الثاني 2015 م } & \multicolumn{5}{|c|}{ الموسم الزراعي الأول 2014 م } & \multirow{3}{*}{ (كجم/ هكتار) } & \multirow{3}{*}{ الكثافة النباتية (نبات/ } \\
\hline \multicolumn{5}{|c|}{ مواعيد الزراعة } & \multicolumn{5}{|c|}{ مواعيد الزراعة } & & \\
\hline المتوسط & سبتمبر 26 & سبتمبر 12 & أغسطس & أغسطس & المتوسط & سبتمبر 26 & سبتمبر 12 & أغسطس & أغسطس & & \\
\hline 0.10 & 0.08 & 0.09 & 0.11 & 0.14 & 0.08 & 0.06 & 0.07 & 0.09 & 0.11 & صفر & \\
\hline 0.13 & 0.10 & 0.11 & 0.14 & 0.17 & 0.11 & 0.08 & 0.10 & 0.12 & 0.14 & 80 & 12320 \\
\hline 0.15 & 0.11 & 0.14 & 0.17 & 0.20 & 0.13 & 0.10 & 0.12 & 0.14 & 0.17 & 120 & 133333 \\
\hline 0.19 & 0.16 & 0.18 & 0.21 & 0.23 & 0.16 & 0.13 & 0.15 & 0.18 & 0.20 & 160 & \\
\hline
\end{tabular}




\begin{tabular}{|c|c|c|c|c|c|c|c|c|c|c|c|}
\hline 0.14 & 0.11 & 0.13 & 0.16 & 0.18 & 0.12 & 0.09 & 0.11 & 0.13 & 0.15 & & المتوسط \\
\hline 0.11 & 0.08 & 0.10 & 0.13 & 0.15 & 0.09 & 0.06 & 0.07 & 0.10 & 0.13 & صفر & \multirow{4}{*}{222222} \\
\hline 0.15 & 0.11 & 0.13 & 0.17 & 0.19 & 0.12 & 0.09 & 0.11 & 0.13 & 0.16 & 80 & \\
\hline 0.19 & 0.16 & 0.18 & 0.20 & 0.22 & 0.15 & 0.12 & 0.15 & 0.16 & 0.18 & 120 & \\
\hline 0.21 & 0.19 & 0.21 & 0.22 & 0.25 & 0.18 & 0.15 & 0.17 & 0.18 & 0.22 & 160 & \\
\hline 0.16 & 0.13 & 0.15 & 0.18 & 0.20 & 0.13 & 0.10 & 0.12 & 0.14 & 0.17 & & المتوسط \\
\hline 0.12 & 0.08 & 0.11 & 0.13 & 0.15 & 0.09 & 0.07 & 0.08 & 0.09 & 0.13 & صفر & \multirow{4}{*}{250000} \\
\hline 0.15 & 0.12 & 0.15 & 0.17 & 0.19 & 0.13 & 0.10 & 0.12 & 0.14 & 0.16 & 80 & \\
\hline 0.18 & 0.15 & 0.18 & 0.20 & 0.21 & 0.15 & 0.12 & 0.14 & 0.16 & 0.19 & 120 & \\
\hline 0.19 & 0.13 & 0.19 & 0.23 & 0.24 & 0.19 & 0.15 & 0.17 & 0.21 & 0.23 & 160 & \\
\hline 0.16 & 0.12 & 0.15 & 0.18 & 0.20 & 0.14 & 0.11 & 0.12 & 0.15 & 0.17 & & المتوسط \\
\hline \multicolumn{5}{|c|}{0.02} & \multicolumn{5}{|c|}{0.01} & الكثافة النباتية & \multirow{3}{*}{ 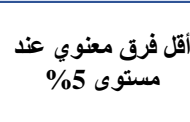 } \\
\hline \multicolumn{5}{|c|}{0.02} & \multicolumn{5}{|c|}{0.01} & التسميد النتروجيني & \\
\hline \multicolumn{5}{|c|}{0.01} & \multicolumn{5}{|c|}{0.01} & مواعيد الزراعة & \\
\hline
\end{tabular}

pp. 249-252, (CF.CAB Abstr. 200230134522008 / $08-2002$ / 07), 2001.

[12] G. Kathiresan, "Response of sesame (Sesamum indicum L.) Genotype to levels of nutrients and spacing under different Seasons". Indian J. Agron. vol. 47, no.4, pp. 537-540, 2002.

[13] م. م. ع. نصيب، "استجابة السمسم (Sesamum indicum L.)

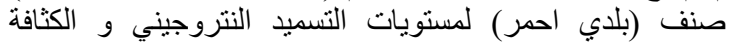

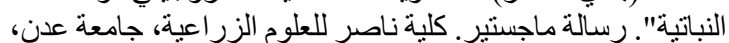

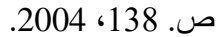

[14] A. M. Abdel-Wahab, A. Awaad, H. M. AbdelMottaleb, M. S. H. A. Yousef and E. E. A. Abdellattief, "The response of two Sesame cultivars to irrigation regimes and Fertilization Under surface and drip irrigation system: 2- yield, yield Components and wue". The 11th conference of Agrononmy Dept. Fac. Agric. Assiut. Univ., pp.343-339, 2005.

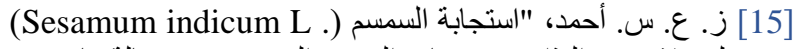
لمعدلات من البذار ومستويات التسميد النتروجيني. رسالة التهاتة ماجستير

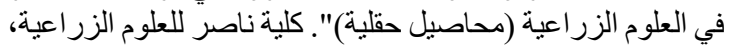
جامعة عدن، ص. 118 118، 2006.

[16] ع. أ. ح. السقاف، "تأثثر بعض عند المعاملات الزراعية على نمو

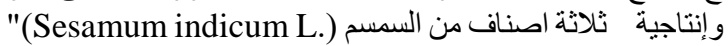
رسالة دكتور ناه الفلسفة (Ph.D) في العلوم الزراعية (محاصيل

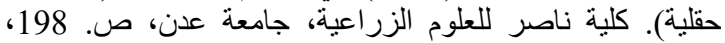

.2009

[17] H. A. Awaad and H. A. Basha, "Yield and yield analysis of some sesame genotypes grown under plant population densities in newly reclaimed sandy soils", Zagazig J. Agric. Res., vol. 27, no.2, pp. 239253, 2000.

[18] Hassan and S. M. A. Hussein, "Sesame Performance as affected by seeding rate and nitrogen Levels under drip irrigation system in newly cultivated Sandy soil I - Yield and Yield attributes". Annals of Agric. Sci. Moshtohor, vol. 38, no. 1, pp. 65-73, 2000.

[19] A. Y. Allam, "Effect of gypsium, nitrogen Fertilization and hill Spacing on seed and oil yields

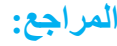

[1] ع ع. ع. السقاف، "إنتاج محاصيل صناعية". سلسلة الكتاب الجامعي (19)، دار جامعة عدن للطباعة والنشر، الجمهورية اليمنية، ص. صلية الجية .2004، 245

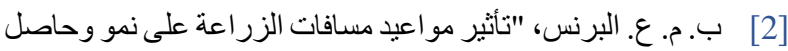

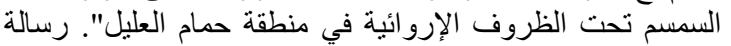

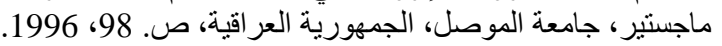

[3] F A O, 2012. http://Faostat.Fao.Org/sit/339/default.Aspx.

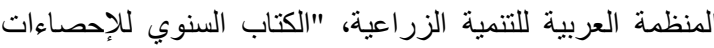

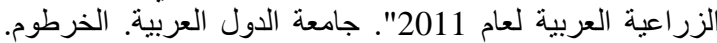

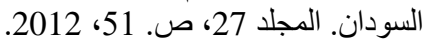

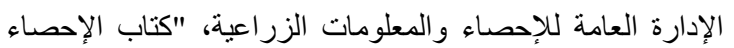
الزراعي لعام (2011)". وزارة لإدة الزراعة الزعة والرية الزية الجمهورية الإحهية

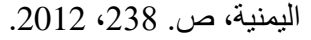

[6] G. B. Suryavanshi, V. S. Pawar and S.K. Ransing, "Effect of sowing dates On yield attributes of sesame". Annals of plant physiology. vol. 4, no.2, pp. 259 -275. (CAB Abstr.1990-1991), 1990.

[7] M. V. Dhoble and N. M. Sukhadia, "Study on. productivity and Economics of different Kharif crops as influenced by varying Dates of sowing for aberrant weather situation under dry Land conditions". Imdian. J. Agron. vol. 35, pp. 223 229, 1990.

[8] Abu-Hagaza and M. Nagah, "Response of sesame to date of Planting, nitrogen levels and plant density", Egypt. J. Appl. Sci, vol. 6, no.7, pp. 55 - 65, 1991.

[9] هـ. ع. م. القزيفي، "تأثير مواعيد الزراعة على صفات النمو،

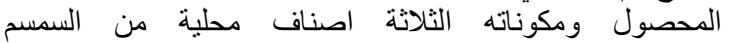

(Sesamum indicum L .)

الزراعية (محاصيل حقلية). كلية ناصر للعلوم الزراعية. جامعة العية عدن، ص. 65، 65، (ماهن 2005.

[10] Khaltal and M. Dalia, "studies for improving potential of some sesame MSC", Thesis. Fac. Of Agric. Cairo Univ. Egypt, p.148, 2001.

[11] A. K. Patra, "Yield and quality of sesame (Sesamum indicum L.) as Influenced by $\mathrm{N}$ and $\mathrm{P}$ during pastrainy season". Ammals of Agric. Res. vol. 22, no.2, 
growth and yield of Sesame in Mediterranean type of enaironment". Asian- Journal of plant science. vol. 3, no.5, pp. 610 - 613 (Cap Abstracts), 2004.

[23] م. ا. امان، م. م. يوسف، "كيمياء وتحليل الأغذية". الطبعة الأولى. دار المعارف الحديثة. الاسكندرية. جمهورية مصر العربية، صلية ص.

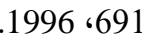

[24] G. W. Snedecor and W. G. Cochran, "Statistical methods 8th Ed". Iowa state Univ. Press Ames. Iowa, U.S.A, 1989.

[25] خ. م. الراوي، ع. خلف الله، "تصميم وتحليل التجارب الزراعية".

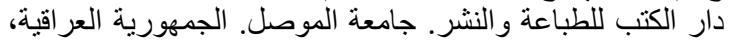

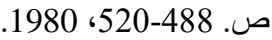

of sesame cultivated on Sandy soil". Assiut J. of Agric. Sci. vol. 33, no.4, pp. 1-16, 2002.

[20] K. A. Abdel-Rahman, A. Y. Allam, A. H. Galal and B. A. Bakry, "Response of sesame to sowing dates, nitrogen Fertilization and plant populations in sandy soil". Assiut J Journal of Agricultural Science, vol. 34, no.3, pp. 1-13, 2003.

[21] A. B. Bakry, "Effect of planting date, population density and nitrogen Fertilization level on yield and its components of sesame (Sesamum indicum L.)" Thesis Master of Science in Agron. Fac. Of Agric. Assiut. Univ. p.63, 2003.

[22] Calishan, S. M. Arslan, H. Arioglu and N. Zsler, "Effect of planting Method and plant population on

\section{RESEARCH ARTICLE}

\section{RESPONSE OF SESAME YIELD (SESAMUM INDICUM L.) CHARACTERS AND ITS COMPONENTS TO SOME AGRICULTURAL TREATMENTS}

\section{Yaser Mohammed Ali Ahmed 1,*, Rakiba Mehammed Abdulla Fadel ${ }^{2}$, Zaid Othman Salem Ahmed ${ }^{2}$}

${ }_{1}^{1}$ Department of Biology, Faculty of Education - Toor Albaha, University of Aden
${ }^{2}$ Department of Agronomy and Agricultural plant, Nasser`s Faculty of Agricultural Sciences, University of Aden

*Corresponding author: Zaid Othman Salem Ahmed; E-mail: ziadothmanaljuri@gmail.com

Received: 08 November 2020 / Accepted: 21 December 2020 / Published online: 30 December 2020

\section{Abstract}

A field experiment was carried out at the farm of Nasser's Faculty of Agricultural Sciences, the university of Aden in Lahej governorate during the two seasons 2011 and 2012 to study the response of sesame (Sesamum indicum L.) cultivar (Balady Red) to sowing dates, Nitrogen levels and plant density on growth, yield and its components characters and its interactions.

1. It could be concluded from this study that sowing dates had a significant effect on all yield and components characters. The highest values of all yield and its components characters were obtained from early sowing date (15 August) during the two seasons.

2. Increasing nitrogen levels up to (160 kg N/hectare) significantly increased all yield and components characters during the two seasons.

3. Increasing plant density up to (250000 plant/hectare) gave a significant increase in seed yield/hectare, oil yield/hectare, and yield of crude protein/hectare.

4. Plant density up to (133333 plant/hectare) increased significantly the number of capsules/plant, seed index, seed yield/plant, seed oil content $\%$ and seed crude protein content $\%$.

5. Plant density up to (222222 plant/hectare) increased significantly seed crude protein content $\%$ and crude protein yield (Mt/hectare).

\section{Keywords: Sesame, Sowing dates, Nitrogen levels, Plant density.}

$$
\text { كيفية الاقتباس من هذا البحث: }
$$

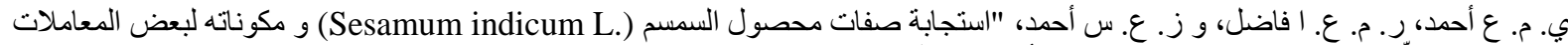

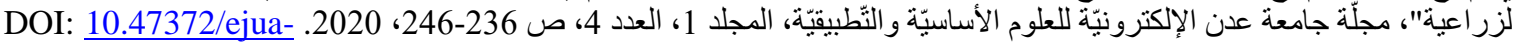

حقوق النشـر C) 2020 من قبل المؤلفين. المرخص لها EJUA، عدن، اليمن. هذه المقالة عبارة عن مقال مفتوح الوصـول يتم توزيعه بموجب شروط و أحكام ترخيص (CC BY-NC 4.0 بون فين 